Foss. Rec., 23, 117-140, 2020

https://doi.org/10.5194/fr-23-117-2020

(C) Author(s) 2020. This work is distributed under

the Creative Commons Attribution 4.0 License.

\title{
Two new species of Mennerotodus Zhelezko, 1994 (Chondrichthyes: Lamniformes: Odontaspididae), from the Paleogene of the southeastern United States
}

\author{
David J. Cicimurri ${ }^{1}$, Jun A. Ebersole ${ }^{2}$, and George Martin ${ }^{3}$ \\ ${ }^{1}$ South Carolina State Museum, 301 Gervais Street, Columbia, SC 29201, USA \\ ${ }^{2}$ McWane Science Center, 200 19th Street North, Birmingham, AL 35203, USA \\ 3 independent researcher: 641 Apache Street, Auburn, AL 36830, USA
}

Correspondence: David J. Cicimurri (dave.cicimurri@scmuseum.org)

Received: 2 April 2020 - Revised: 11 June 2020 - Accepted: 16 June 2020 - Published: 22 July 2020

\begin{abstract}
Mennerotodus Zhelezko, 1994, is an extinct lamniform shark known to occur in Paleogene strata of the Tethyan region of Asia and Europe. Although only a single species has been named, multiple subspecies have been erected and used as biostratigraphic tools in Asia. The genus has not been reported with confidence outside of the Tethyan region, but we have identified two new species of Mennerotodus from Paleogene deposits of the southeastern United States. Mennerotodus mackayi sp. nov. is described by teeth occurring in the lower Paleocene (Danian Stage) Pine Barren Member of the Clayton Formation of southern Alabama. A middle Eocene (Bartonian) species, Mennerotodus parmleyi sp. nov., is based on material occurring in the Clinchfield Formation in central Georgia. The early Paleocene record could indicate a North American origin for Mennerotodus relatively soon after the K-Pg event, with subsequent radiation to other parts of the world. The genus is likely more widely distributed than is currently known, but teeth can easily be overlooked due to their similarity to other taxa.
\end{abstract}

\section{Introduction}

Mennerotodus Zhelezko, 1994, is an extinct odontaspidid shark that was originally named based on middle Eocene (Bartonian) teeth from Kazakhstan. The teeth were distinguished by their overall shape and the development of denticulation at the base of the main cusp. Although the genus Mennerotodus was named by Zhelezko in 1989 (p. 17), no type specimens were designated, nor were any specimens il- lustrated in this original publication, so the generic name was therefore a nomen nudum. Zhelezko (in Zhelezko and Kozlov, 1990, p. 175) used the name again soon thereafter, but the genus was not formally recognized until teeth were described and figured by Zhelezko in 1994. Zhelezko (1994) erected three species of Mennerotodus, but only the type species, M. glueckmani Zhelezko, 1994, is currently recognized (Cappetta, 2012). Within this species, Zhelezko (1994) named three subspecies, including $M$. g. glueckmani, $M . g$. usunbassi, and M. g. boktensis. There was an intent to utilize the subspecies as biostratigraphic tools, as the type stratum for $M . g$. boktensis is the middle Eocene (Lutetian) Amankisilit Formation, M. g. glueckmani is from the lower Shorym Formation (Bartonian), and M. g. usunbassi was in the upper Shorym Formation (Bartonian; Zhelezko, 1994). Cappetta (2012) reported the temporal distribution as late $\mathrm{Pa}$ leocene (Thanetian) to late Eocene (Priabonian).

The two other Mennerotodus species, M. borealis Zhelezko, 1994, and M. karpinsky (Menner, 1928), are no longer considered to belong to this genus. These species were later moved to the genus Borealotodus Zhelezko and Kozlov, 1999, and apparently the subtle differences between Borealotodus and Mennerotodus were not evident when the morphologies were originally described. Malyshkina (2006a) concluded that Borealotodus karpinsky (Menner, 1928) is a junior synonym of Mennerotodus glueckmani, but Cappetta (2012) maintained B. karpinsky to be valid. Cappetta (2012) noted the similarities between Borealotodus and Mennerotodus but concluded that the genera were distinguished by their anterior teeth. According to Cappetta (2012), Mennerotodus anterior teeth differ from 


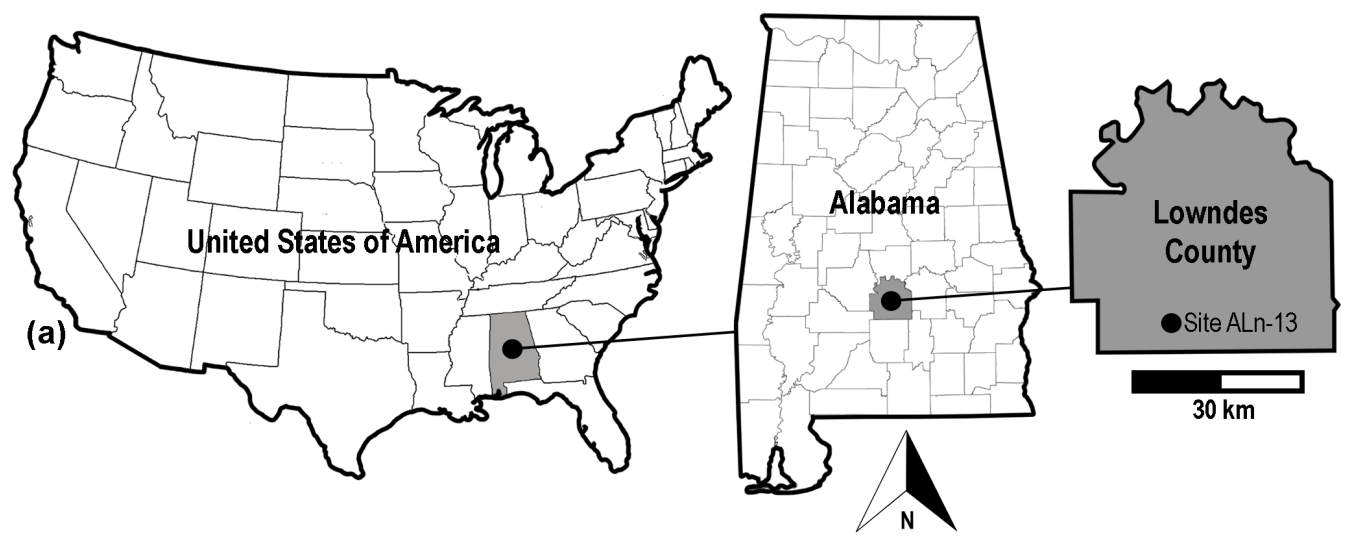

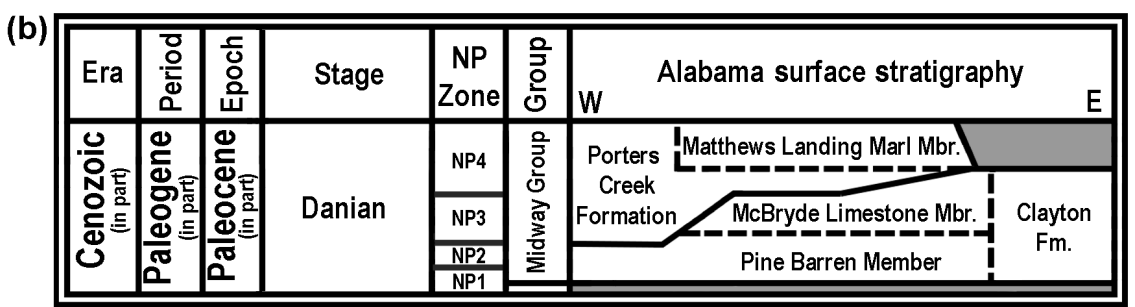

Figure 1. Generalized location and surface stratigraphy of site ALn-13, Lowndes County, AL, USA. (a) Geographic maps showing the location of site ALn-13 in country, state, and county contexts. (b) Danian surface stratigraphy in Alabama, USA. Shaded areas on the stratigraphic chart represent unconformities.

those of Borealotodus in being more sigmoidal and lingually curved in profile view, and the main cusp is narrower basally and more sharply tapered apically.

Dutheil et al. (2006) identified Mennerotodus in Thanetian deposits of the Paris Basin, thereby extending the geographic range of the genus to western Europe. Although the authors did not attribute the material to any species, they observed that the teeth were relatively common. Ebersole et al. (2019) were the first to recognize the genus in North America based on a sample of middle Eocene (Bartonian) specimens from southern Alabama.

Herein we describe two new species of Mennerotodus from Paleogene strata of the southeastern United States. The older of the two species was recovered from the lower Paleocene (Danian Stage) Pine Barren Member of the Clayton Formation of southeastern Alabama (Fig. 1a). The other species derives from the middle Eocene (Bartonian-Priabonian) Clinchfield Formation in central Georgia (Fig. 2a). We also provide additional morphological features that allow for differentiation of Mennerotodus from similarly shaped teeth of other, coeval genera. Heterodonty within the two new species is discussed, and artificial dentitions of each species are presented. In addition, we comment on the paleobiogeographic and stratigraphic distribution of Mennerotodus in North America.

\section{Stratigraphic framework and age}

\subsection{Pine Barren Member of the Clayton Formation}

The Danian type specimens described herein were all collected by one of the authors (GM) at site ALn-13 in Lowndes County, Alabama, USA (Fig. 1b). This sample of teeth was obtained by surface collecting specimens that were eroding directly from a roadside outcrop consisting of numerous beds of the Pine Barren Member of the Clayton Formation. In Butler, Lowndes, and Wilcox counties of Alabama, the Clayton Formation is divided into two members, including the Pine Barren Member and overlying McBryde Limestone Member (Raymond et al., 1988). The Pine Barren Member is the lowermost Paleocene unit exposed in Alabama, and it is separated from the underlying Upper Cretaceous (Maastrichtian) Prairie Bluff Chalk by a Type 1 unconformity (Mancini et al., 1989). In central Alabama the Pine Barren Member can attain a thickness of up to $45 \mathrm{~m}, 8$ vertical meters of which are exposed at site ALn-13. The thick section of the Pine Barren Member in this area spans across parts of calcareous nannoplankton zones NP1 to NP3 (Mancini and Tew, 1990).

The geology at site ALn-13 has been described in detail by Mancini (1981), Mancini et al. (1989), Savrda (1993), and Udgata (2007). Overall, the Clayton Formation is believed to represent shallow marine and marginal marine settings (Mancini et al., 1989). However, at site ALn-13 the Pine Barren Member exposures are thought to have been deposited in an estuarine setting (Savrda, 1993) during a high- 

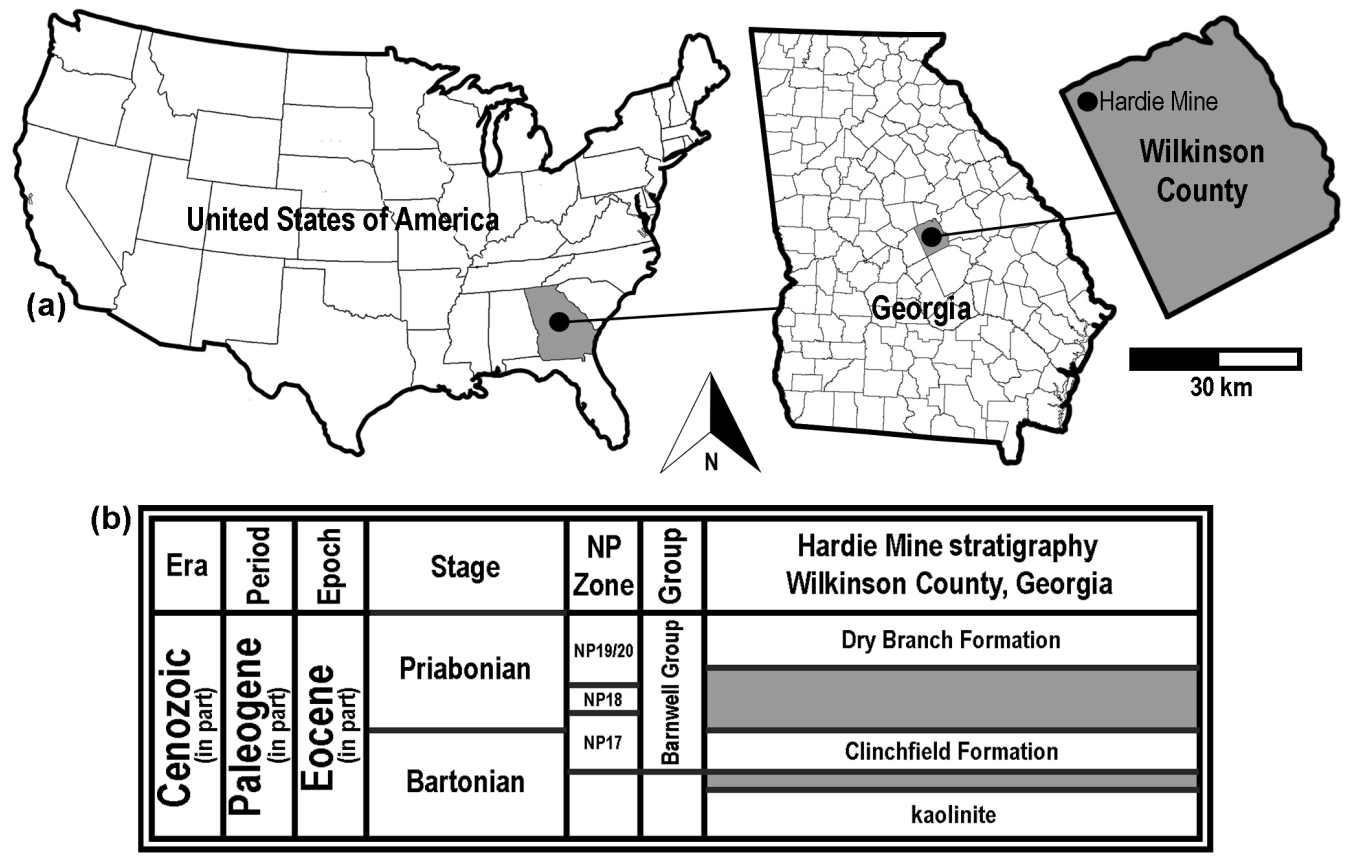

Figure 2. Generalized location and surface stratigraphy of the Hardie Mine site, Wilkinson County, GA, USA. (a) Geographic maps showing the location of the Hardie Mine site in country, state, and county contexts. (b) Middle to late Eocene lithostratigraphic units formerly exposed in the mine. Shaded areas on the stratigraphic chart represent unconformities.

stand systems tract (Mancini et al., 1989; Udgata, 2007). Udgata (2007) subdivided the Pine Barren Member exposures at site ALn-13 into 30 informal units, with beds 14 30 consisting largely of alternating sandy micritic limestones or marlstones and indurated fine- to medium-grained sandy mudstones. Although all of the exposed beds at site ALn-13 are fossiliferous, the Danian teeth reported herein were concentrated within the lower two-thirds of the section, within Udgata's (Udgata, 2007) beds 14 to 18.

It should be noted that Mancini et al. (1989) reported the occurrence of reworked Maastrichtian microfossils within the Pine Barren section at site ALn-13, and extremely rare Cretaceous macrovertebrate fossils were collected from the outcrop by one of us (GM). These macrofossils include teeth from a pycnodont fish, Anomoeodus sp., and the sharks Squalicorax kaupi (Agassiz, 1843) and Serratolamna serrata (Agassiz, 1843). Despite the presence of these reworked specimens, the Mennerotodus teeth collected from this locality all appear to be Danian in origin, as this genus is abundant in the Pine Barren section but absent from any of the Cretaceous units in the state (JAE, unpublished data).

\subsection{Clinchfield Formation}

The Bartonian type specimens described below were obtained from the Clinchfield Formation, the basal lithostratigraphic unit within the middle to late Eocene Barnwell Group. The fossils were collected from within a defunct kaolinite surface mine, locally known as the Hardie Mine, in Wilkinson County, Georgia, USA (Fig. 2a). At this site, the Riggins Mill Member of the Clinchfield Formation was exposed, and this formation was disconformably underlain by unfossiliferous middle Eocene kaolinite and overlain by orange-red, cross-bedded sand of the Priabonian-aged Dry Branch Formation (Fig. 2b). The Clinchfield Formation represents estuarine deposits, and Parmley and Cicimurri (2003) reported that the unit accumulated during calcareous nannofossil zone NP17.

The majority of the specimens in our sample was recovered from spoil piles of the Clinchfield Formation. At the Hardie Mine the apparent mining procedure was to remove Dry Branch Formation deposits from the site and then strip away the Clinchfield Formation and place it in piles throughout the mine. Close examination of in situ kaolinite, Clinchfield Formation, and superjacent Dry Branch Formation deposits showed that the upper and lower confining units were unfossiliferous, and we can confidently say that the specimens we describe herein were all derived from the Clinchfield Formation (Parmley and Cicimurri, 2003).

In their correlation of lithostratigraphic units within the southeastern United States, Huddleston and Hetrick (1986) showed that the Clinchfield Formation was laterally equivalent to the Moodys Branch Formation of the Gulf Coastal Plain. Additionally, both units were placed at the base of planktonic foraminifera zone P16. However, Albright et al. (2019) recently placed the Clinchfield Formation within Zone P14 and the lower half of Zone P15, thus making this 
unit time equivalent to the Bartonian (Zone NP17) Gosport Sand in Alabama and Mississippi, USA.

\section{Material and methods}

During our study we examined a number of Mennerotodus specimens from several different states and lithostratigraphic units. The type specimens for the Danian taxon are all housed at the McWane Science Center (MSC) in Birmingham, Alabama, USA, and the Bartonian type specimens are housed at the South Carolina State Museum (SC) in Columbia, USA. Unfortunately, the Hardie Mine has been reclaimed and is no longer available to collectors, but additional fossils from this mine are housed at SC; the Georgia College and State University in Milledgeville, USA; and the Mississippi Museum of Natural Science (MMNS) in Jackson, USA. Mennerotodus teeth from the Gosport Sand in Alabama are part of the Alabama Museum of Natural History (ALMNH) collections in Tuscaloosa, USA, and additional specimens from the Clayton Formation in Alabama are housed at MMNS, MSC, and SC. A sample of teeth from middle to late Eocene deposits in St Francis County, Arkansas, were examined in the collections of MMNS and the United States National Museum of Natural History (NMNH) in Washington, DC; Danian specimens from Arkansas were examined in the MMNS collections.

The jaws of several extant selachian taxa housed at SC, MSC, and NMNH were also closely examined as part of our study. We found that the Mennerotodus teeth discussed herein are remarkably similar to those of the extant sand tiger shark, Carcharias taurus Rafinesque, 1810. Two sets of C. taurus jaws from the SC collection (SC200.120.6 and SC86.62.2) and an unnumbered jaw from the Gordon Hubbell Collection in Florida were used as models for reconstructing the artificial dentitions for the new Mennerotodus species. Applegate (1965) commented on the utility of using dentitions of extant sharks to elucidate the morphological variations among fossil teeth, and $C$. taurus has previously been used as the basis for reconstructions of dentitions of extinct species like Araloselachus cuspidatus (Agassiz, 1843; Purdy et al., 2001; Reinecke et al., 2001), A. vorax (Le Hon, 1871; De Schutter, 2011), and even Striatolamia Glikman, 1964 (Cunningham, 2000).

There are inter- and intrageneric variations in tooth counts within Odontaspididae (Bigelow and Schroeder, 1948; Applegate, 1965; Sadowsky, 1970; Shimada, 2001, 2004), and we concede that the artificial Mennerotodus dentitions as we reconstructed them may not have matched $C$. taurus exactly. Although the number of intermediate, lateral, and posterior files may vary within $C$. taurus, the number of anterior files does not (Applegate, 1965; Sadowsky, 1970; Lucifora et al., 2003), and we presume the same held true within the Mennerotodus dentition. Our reconstructions are based on isolated teeth and rely heavily on comparisons with extant $C$. taurus, and these hypotheses can best be tested only through the discovery and analysis of tooth-bearing jaws of the extinct species (e.g., Ward, 1988). To create the artificial dentitions, in particular to account for ontogenetic size differences between the teeth, the fossil teeth were scaled to reflect the size range of teeth within the $C$. taurus dentitions. The photographs of certain teeth were reversed when necessary to help complete the artificial dentitions (i.e., a tooth from the left jaw to represent a file from the right jaw).

Elasmobranch tooth terminology has varied within the literature, and terms like symphyseal, parasymphyseal, medial, alternate, anterior, intermediate, lateral, and posterior have been used to identify the location of a tooth within the jaws of galeomorph sharks. The terms "symphyseal" (Leriche, 1905), "medial" or "median" and "alternate" (Applegate, 1965), and "parasymphyseal" (Cappetta, 1987, 2012) have all been used to identify teeth occurring directly on or immediately adjacent to the jaw symphysis. However, alternate has not been adopted and medial or median has generally only been used to identify the very wide, centrally located teeth within batoid dentitions like those of the Myliobatidae (i.e., Purdy et al., 2001; Cappetta, 2012). Siverson (1999) advocated restricting the use of symphyseal to only those teeth occurring at the midline of the jaw, where the right and left halves articulate, as seen, for example, in the upper jaw of extant Galeocerdo cuvier (Lesueur, 1822; SC2000.120.10) and Squalus acanthias Linneaus, 1858 (SC96.77.4). Such a restriction in terminology would therefore result in a tooth file immediately adjacent to the symphysis being considered a parasymphyseal or anterior position (Siverson, 1999; Cunningham, 2000). Extant lamniform sharks like Carcharodon carcharias (Linnaeus, 1758; SC86.62.1) and Isurus paucus Guitart-Manday, 1966 (SC86.186.2), lack teeth directly on the symphysis of the upper and lower jaws, and the first tooth file is considered an anterior tooth. We follow the convention that, within the Meckel's cartilages of lamniform sharks, the tooth file immediately adjacent to the symphysis is the first anterior position. This file occurs within a mesial hollow along with other anterior teeth, all of which are distinctly separated from the elongated furrow that contains the lateral and posterior tooth files. On the palatoquadrates of lamniform sharks, a cartilage bar separates the mesial and distal hollows, and teeth occurring just on the mesial side of the bar are identified as occupying an "intermediate" position (Cappetta, 1987, 2012; Siverson, 1999; Shimada, 2001, 2002a-c, 2004). These teeth are much reduced in size compared to the preceding anterior teeth and succeeding lateral teeth, and this phenomenon occurs in C. taurus dentitions (SC86.62.2 and SC2006.120.6). In contrast to an obvious morphological difference between the anterior and lateral files of lamniform dentitions, the transition from lateral to posterior files can be more gradational and the term "lateroposterior" has been applied to tooth files occurring distally to the intermediate file of the upper dentition and the last anterior file in the lower dentition (Siverson 1999). For the purposes of this report, we 
recognize anterior, intermediate, lateral, and posterior tooth files when identifying isolated teeth.

All of the specimens illustrated herein were photographed with a Nikon D80 digital SLR with a Tamron SP macro lens. Photographs were rendered and the accompanying figures designed in Adobe Photoshop CC 2017. Higher taxonomic rankings follow Nelson et al. (2016).

\section{Systematic paleontology}

Class Chondrichthyes Huxley, 1880

Subclass Elasmobranchii Bonaparte, 1838

Infraclass Euselachii Hay, 1902

Division Selachii Cope, 1871

Superorder Galeomorphii Compagno, 1973

Order Lamniformes Berg, 1958

Family Odontaspididae Müller and Henle, 1841

Genus Mennerotodus Zhelezko, 1994

\section{Type species}

Mennerotodus glueckmani Zhelezko, 1994, middle Eocene (Bartonian), Shorym Formation, Mangyshlak, Kazakhstan.

\section{Emended generic diagnosis}

Mennerotodus teeth can be divided into anterior, intermediate, lateral, and posterior tooth groups. The upper dentition consists of three anterior tooth files, whereas the lower dentition includes four anterior files, and in general the anterior teeth have a tall and narrow triangular main cusp, with a highly convex lingual face and a virtually flat labial face. The enameloid on the main cusp is generally smooth, but faint longitudinal ridges have been observed on the lower half of the crown on a small number of teeth. The main cusp is sinuous in profile view, and the teeth have a single pair of small and conical lateral cusplets. The cutting edges on the main cusp are incomplete and do not extend to the base of the crown. On some teeth one or more denticles are present between the cutting edge and the lateral cusplets, and at times this denticle is expressed as a small ridge that is separate from the main cutting edge. The root lobes are thin with rounded extremities, and a conspicuous nutritive groove is located on a robust lingual root protuberance. The interlobe area on the anterior teeth is generally U-shaped. The first lower anterior tooth is conspicuously smaller in size than the other anterior teeth, and it has an extremely narrow main cusp and elongated distal root lobe. The main cusp on the third upper anterior tooth has a slight mesial bend and an extended mesial root lobe.
The intermediate teeth have a much lower main cusp than the anterior teeth and are smaller in overall size. The height of the root is greater than the height of the crown, and the teeth are labiolingually compressed. The main cusp has a slight distal bend, and a single pair of lateral cusplets are extremely tall in comparison to the overall height of the main cusp.

The lateral teeth are similar to the anterior teeth but have a shorter and more broadly triangular main cusp. The main cusp has a profile that is flat to only slightly sinuous, and this sinuosity is not to the degree seen on anterior teeth. The lateral teeth have one pair or very rarely two pairs of lateral cusplets, and these cusplets are larger and more triangular than those on the anterior teeth. When a second pair of cusplets occurs, they are generally diminutive and united to the outer edge of the larger, more medial cusplet. Denticles occur at the base of the main-cusp cutting edge (medial to the lateral cusplets) on about $30 \%$ of the teeth. These denticles are larger than those observed on the anterior teeth and can occur in greater numbers. Although the crown faces are generally smooth, fine vertical ridges are developed on some teeth. The root lobes are short and divergent and have rounded extremities, and the interlobe area can be U-shaped or V-shaped. A conspicuous nutritive groove occurs on a robust lingual root boss. The main cusp is distally inclined on the upper lateral teeth but more erect in the lower lateral files.

The posterior teeth are similar to the lateral teeth but can be differentiated by their having a labiolingual width that is nearly equal to the overall height of the tooth. The main cusp is extremely low and triangular $(6 \mathrm{~B}, 12 \mathrm{~A})$, and the teeth have a single pair of wide and triangular lateral cusplets. The teeth have a shallow and V-shaped interlobe area, and the upper posterior teeth have a more distally inclined main cusp than those in the lower posterior positions.

Mennerotodus mackayi sp. nov.

LSID urn:lsid:zoobank.org:act:2F9AABDC-5E094962-9D81-2EC13302109B

2011 Carcharias cf. whitei, Becker et al., p. 19, figs. 4.5, 4.6. 2019 Carcharias sp., Maisch et al., fig. 7g.

\section{Etymology}

The species is named for John L. Mackay, initial President and CEO at McWane Science Center, Birmingham, Alabama, USA, in honor of his distinguished career in informal education.

\section{Hypodigm}

MSC 42411 (paratype), first upper right anterior tooth (Fig. 3a-e); MSC 42408 (paratype), second upper right anterior tooth (Fig. 3f-j); MSC 42413 (paratype), third upper left anterior tooth (Fig. 3k-o); MSC 42412 (holotype), first up- 


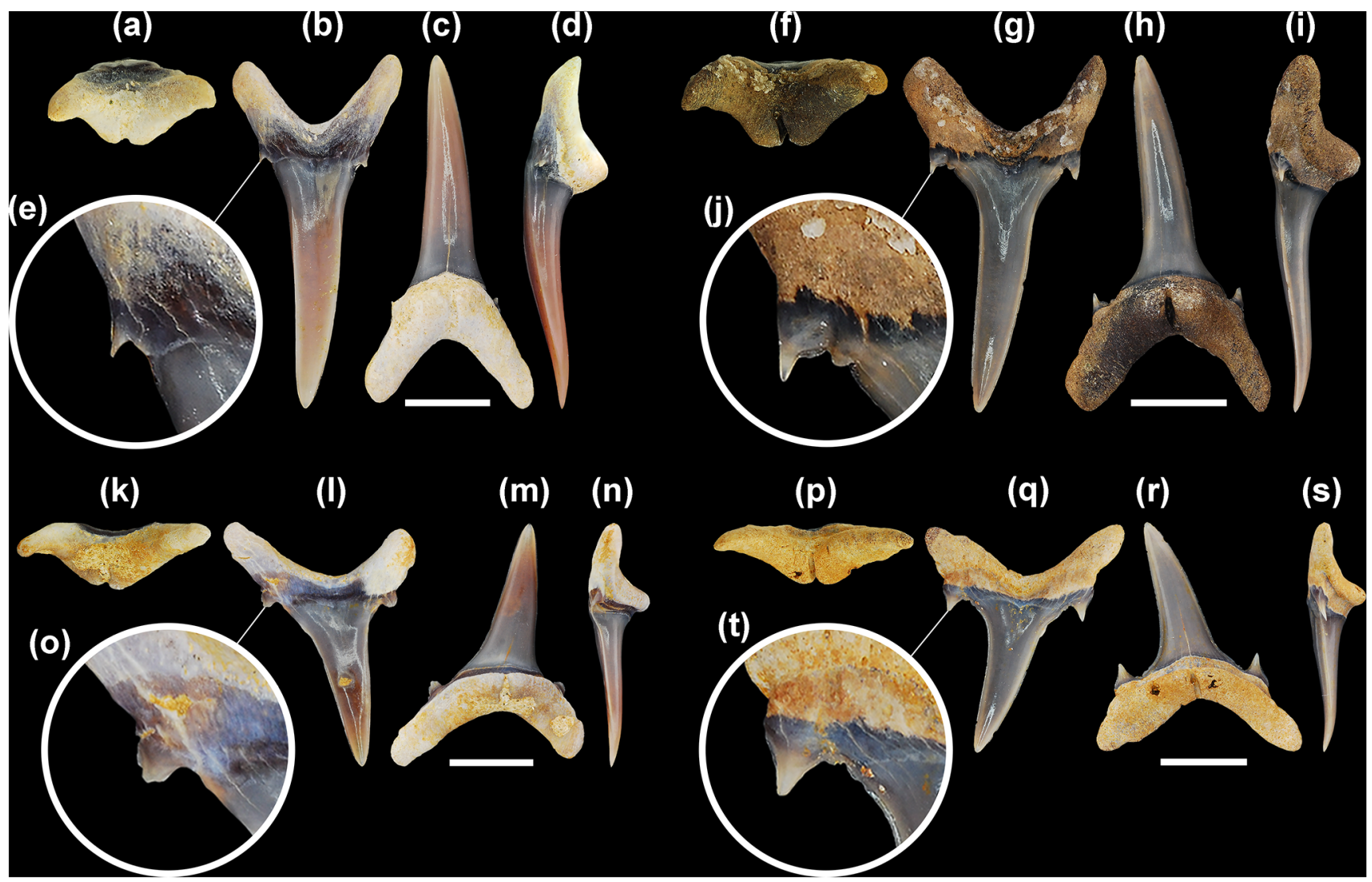

Figure 3. Mennerotodus mackayi sp. nov. upper-dentition hypodigm, Paleocene (Danian) Pine Barren Member of the Clayton Formation, site ALn-13, Lowndes County, Alabama, USA. (a-e) MSC 42411, first upper right anterior tooth (paratype). (a) Basal view. (b) Labial view. (c) Lingual view. (d) Mesial view. (e) Close-up of distal cusplet. (f-j) MSC 42408, second upper right anterior tooth (paratype). (f) Basal view. (g) Labial view. (h) Lingual view. (i) Mesial view. (j) Close-up of distal cusplet and denticle. (k-o) MSC 42413, third upper left anterior tooth (paratype). (k) Basal view. (l) Labial view. (m) Lingual view. (n) Mesial view. (o) Close-up of distal cusplet. (p-t) MSC 42412, upper lateral tooth (holotype). (p) Basal view. (q) Labial view. (r) Lingual view. (s) Mesial view. (t) Close-up of distal cusplet and denticle. Labial at top in (a), (f), (k), and (p). Scale bars $=5 \mathrm{~mm}$.

per right lateral tooth (Fig. 3p-t); MSC 42416 (paratype), upper posterior tooth (Fig. 3u-y); MSC 42407 (paratype), first lower left anterior tooth (Fig. 4a-e); MSC 42405 (paratype), second lower right anterior tooth (Fig. 4f-j); MSC 42410 (paratype), third lower right anterior tooth (Fig. 4k-o); MSC 42406 (paratype), fourth lower left anterior tooth (Fig. 4p-t); MSC 42409 (paratype), lower right lateral tooth (Fig. 4u-y); MSC 42632 (paratype), lower right posterior tooth (Fig. 4zad).

\section{Referred specimens}

MSC 42414, second upper anterior teeth (16 specimens); MSC 42415, second upper anterior teeth (nine specimens); MSC 42417, lower posterior teeth (two specimens); MSC 42418, third upper anterior tooth; MSC 42419, third upper anterior teeth (seven specimens); MSC 42420, third upper anterior teeth (eight specimens); MSC 42421, upper right lateral tooth; MSC 42422, upper right lateral tooth;
MSC 42423, upper right lateral teeth (nine specimens); MSC 42424, upper right lateral teeth (35 specimens); MSC 42425, lower left lateral teeth (11 specimens); MSC 42426, lower right lateral teeth (nine specimens); MSC 42427, first lower anterior tooth; MSC 42428, first lower anterior tooth; MSC 42429, first lower anterior teeth (seven specimens); MSC 42430, third lower anterior teeth (11 specimens); MSC 42431, third lower anterior teeth (nine specimens); MSC 42432, lower lateral teeth (17 specimens); MSC 42433, lower lateral teeth (43 specimens); MSC 42434, first upper anterior teeth (six specimens); MSC 42435, first upper anterior teeth (20 specimens); MSC 42436, second lower anterior tooth; MSC 42437, second lower anterior tooth; MSC 42438, second lower anterior tooth; MSC 42439, second lower anterior teeth (four specimens); MSC 42440, second lower anterior teeth (15 specimens); MSC 42441, fourth lower anterior tooth; MSC 42442, fourth lower anterior teeth (three specimens); MSC 42443, anterior teeth (seven specimens); MSC 42444, upper left lateral teeth (43 specimens); MSC 42445, 


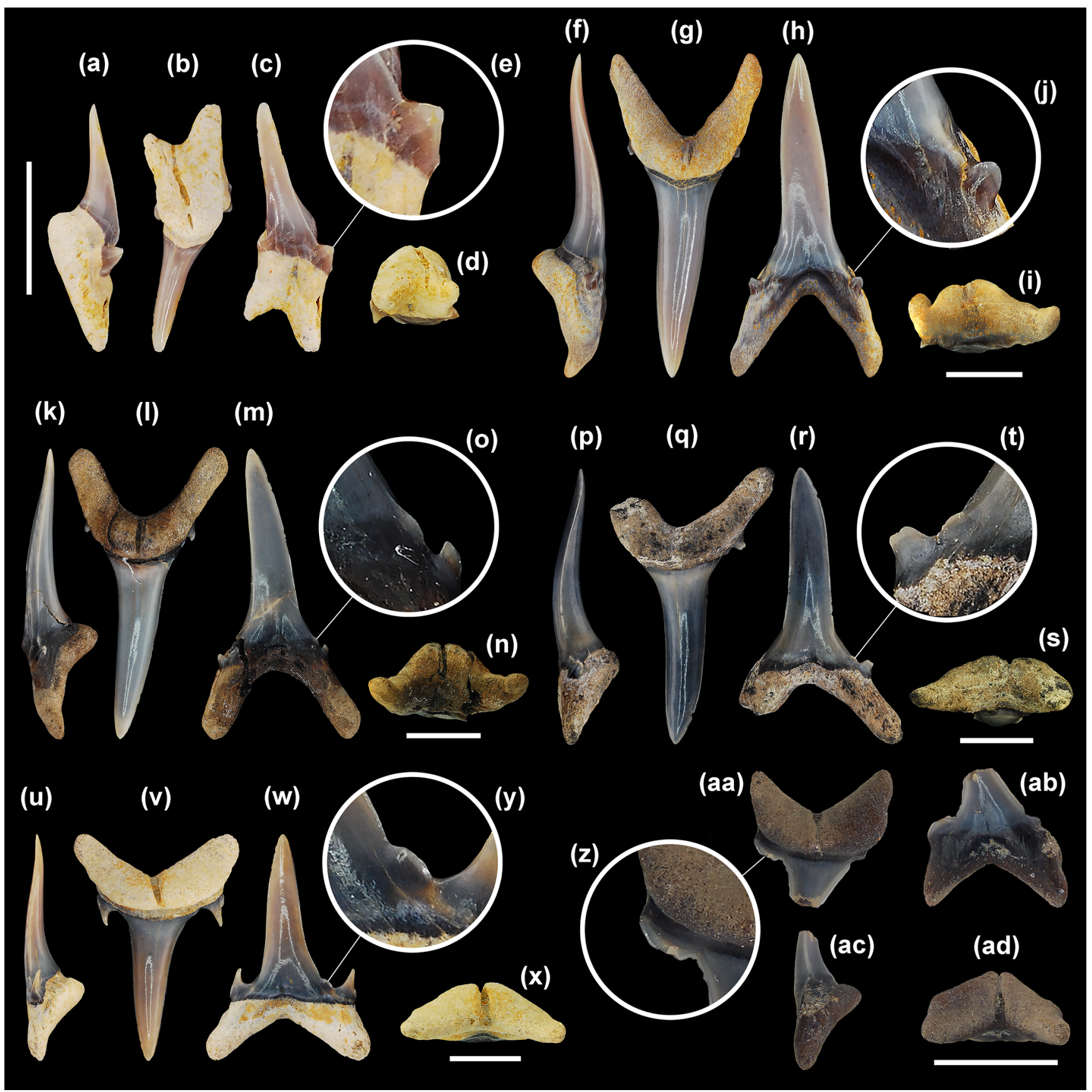

Figure 4. Mennerotodus mackayi sp. nov. lower-dentition hypodigm, Paleocene (Danian) Pine Barren Member of the Clayton Formation, site ALn-13, Lowndes County, Alabama, USA. (a-d) MSC 42407, first lower left anterior tooth (paratype). (a) Distal view. (b) Lingual view. (c) Labial view. (d) Basal view. (e) Close-up of distal cusplet. (f-i) MSC 42405, second lower right anterior tooth (paratype). (f) Distal view. (g) Lingual view. (h) Labial view. (i) Basal view. (j) Close-up of mesial cusplet. (k-n) MSC 42410, third lower right anterior tooth (paratype). (k) Mesial view. (l) Lingual view. (m) Labial view. (n) Basal view. (o) Close-up of mesial denticle and cusplet. (p-s) MSC 42406, fourth lower left anterior tooth (paratype; reversed). (p) Mesial view. (q) Lingual view. (r) Labial view. (s) Basal view. (t) Close-up of mesial denticle and cusplet. (u-x) MSC 42409, lower right lateral tooth (paratype). (u) Mesial view. (v) Lingual view. (w) Labial view. (x) Basal view. (y) Close-up of mesial denticle. (z-ad) MSC 42632, lower right posterior tooth. (z) Close-up of distal cusplet. (aa) Lingual view. (ab) Labial view. (ac) Mesial view. (ad) Basal view. Labial at bottom in (d), (i), (n), (s), (x), and (ad). Scale bars $=5 \mathrm{~mm}$. 
unassigned tooth positions (21 specimens); MSC 42446, unassigned tooth positions (72 specimens); MSC 42493, second upper right lateral tooth; MSC 42494, sixth? upper right lateral tooth; MSC 42495, first upper right lateral tooth; MSC 42496, fifth? upper right lateral tooth; MSC 42497, seventh? upper right lateral tooth; MSC 42498, first lower left lateral tooth; MSC 42499, third lower left lateral tooth; MSC 42500, fourth? lower left lateral tooth; MSC 42501, fifth? lower left lateral tooth; MSC 42502, sixth? lower left lateral tooth; MSC 42633, second lower anterior tooth; MSC 42634, second lower anterior tooth; MSC 42635, fourth lower anterior tooth; MSC 42636, fourth lower anterior tooth; MSC 42718, second upper right lateral tooth; MSC 42719, first lower left lateral tooth.

\section{Type stratum}

Lower Danian (Paleocene) Pine Barren Member of the Clayton Formation, approximately $10 \mathrm{~m}$ above lower contact with the late Maastrichtian (Upper Cretaceous) Prairie Bluff Chalk Formation, zones NP1 to NP3 (Fig. 1b).

\section{Type locality}

Site ALn-13, Lowndes County, Alabama, USA (Fig. 1a). Due to the sensitive nature of the site, the precise location is not provided here, but detailed locality information is on file at MSC and available to qualified researchers.

\section{Description}

First upper anterior teeth. These teeth, not exceeding $25 \mathrm{~mm}$ in total height, are slightly asymmetrical in labial view. The main cusp is very narrow, is slightly distally curving (Fig. 3b-d), and has a weakly sigmoidal profile (Fig. 3d). Mesial and distal cutting edges are sharp, smooth, and subparallel but never reach the base of the main cusp (Fig. 3d). There may be a minuscule tubercle or very short ridge near the base of the main cusp, well separated from the main cutting edge, on one or both sides of the crown. A single pair of diminutive triangular cusplets is located at the crown foot. When present, the short ridge is connected to the lateral cusplet (Fig. 3e). The labial face of the main cusp is smooth and flat except for where basal convexity occurs at each side of the labial crown foot. The lingual face is very convex and generally smooth, although faint longitudinal ridges on the lower half were occasionally observed. The root is bilobate and has a large lingual boss that is bisected by an elongate and deep nutritive groove (Fig. 3a). A conspicuous dental band (often deeply impressed) occurs at the lingual crown foot. Root lobes are rather short and may be cylindrical or mesiodistally compressed, and the mesial lobe is slightly longer than the distal lobe (Fig. 3b, c).

Second upper anterior teeth. In our sample, the largest complete tooth from this file measures $20 \mathrm{~mm}$ in total height, which is smaller than the largest first upper anterior tooth available to us. Larger second upper anterior teeth are present in our sample, but they are incomplete and represented fragmentary specimens. The main cusp is tall and narrow, sharply tapering (Fig. 3g, h), weakly sigmoidal in profile (Fig. 3i), and more distally inclined than the main cusp of the first anterior tooth (Fig. 3h). Cutting edges are subparallel, and although they do not reach the cusp base, the edges extend further basally than on teeth from the first anterior file. The labial face is smooth and flat to very weakly convex, but the lingual face is very convex and may bear faint vertical ridges on the lower half. The main cusp is flanked by a single pair of small cusplets that are triangular, are sharply pointed, and have distinct cutting edges. A short cutting edge or small denticle, well separated from the main cutting edge, may occur on the medial side of one or both lateral cusplets (Fig. 3j). The lingual dental band is conspicuous and may be impressed (Fig. 3h), and the robust lingual root boss bears a thin nutritive groove (Fig. 3f, h). The root is bilobate, and although the lobes are of nearly the same length, the mesial lobe is thin and pointed basally, whereas the distal lobe is wide and rounded basally (Fig. 3g, h).

Third upper anterior teeth. The largest specimens do not measure more than $20 \mathrm{~mm}$ in total height. The main cusp is broad-based but sharply tapering, is strongly distally inclined but with weak mesial curvature (Fig. 31, m), and has only a very weak sigmoidal profile (Fig. $3 n$ ). The labial face is flat and smooth, but the lingual face is moderately convex and usually smooth. The smooth cutting edge is continuous across the entire main cusp. A single pair of broadly triangular cusplets flanks the main cusp, and these cusplets bear sharp cutting edges (Fig. 3o). A small denticle may be located medially to the lateral cusplet, on one or both sides of the main cusp. The lingual dental band is conspicuous and may be impressed (Fig. 3m). The root is bilobate with highly divergent lobes, with the mesial lobe being much more elongated than the distal one (Fig. 31). The lingual boss is thin and shelflike, bisected by a thin nutritive groove (Fig. 3k, n).

Intermediate teeth. No intermediate teeth have been identified in the available sample.

Upper lateral teeth. Upper lateral teeth can be differentiated from the anterior teeth in that the main cusp is labiolingually thinner, flat to only weakly sigmoidal in profile (Fig. 3s), and distally inclined, and the base is broader. The smooth cutting edge is continuous across the entire main cusp, reaching the crown foot. The mesial and distal cutting edges may be straight, but more often the main cusp appears distally curving because the mesial edge is slightly convex and the distal edge straight to concave. One or two tiny denticles may occur on one or both sides of the crown foot, adjacent to lateral cusplets (Fig. 3t). A single pair of broadly triangular, tall, sharply pointed cusplets flanks the main cusp (Fig. 3q). The lingual dental band is impressed. The bilobate root bears a small lingual boss that is bisected by a deep nutritive groove (Fig. 3p, r). Root lobes are rather short, wide, and divergent (Fig. 3r). Within the first few lateral files, the 
mesial root lobe is more elongated and thinner than the distal lobe, but other lateral teeth have more equidimensional root lobes. Total tooth height exceeds root width. Within our sample of upper lateral teeth, it appears that the crown decreases in size but becomes more strongly distally inclined towards the commissure.

Upper posterior teeth. No upper posterior teeth have been identified in the sample.

First lower anterior teeth. Teeth from this file are not known to exceed $15 \mathrm{~mm}$ in total height. The main cusp is very narrow and sharply inclined mesially, may be straight to distally curving, and has a strong lingual curve in profile but is not sigmoidal (Fig. $4 \mathrm{a}-\mathrm{c}$ ). The labial face is smooth and nearly flat, whereas the lingual face is very convex and smooth. Cutting edges are smooth, sharp, and subparallel and extend to the crown foot (Fig. 4e). A single pair of lateral cusplets flanks the main cusp, and in labial view the mesial cusplet appears to be located higher on the tooth than the distal cusplet (Fig. 4c). The cusplets are small, triangular, sharply pointed, and divergent. The root is laterally compressed, weakly bilobate (mesial lobe is shorter and narrower than the distal lobe), and the large lingual boss (Fig. 4a, d) is bisected by an elongate nutritive groove (Fig. 4b). Crown height slightly exceeds root height.

Second lower anterior teeth. Teeth in this position are the largest in the available sample, reaching $24.4 \mathrm{~mm}$ in total height. The main cusp is tall, narrow, and erect and has a sigmoidal profile (Fig. 4f-h). The labial face is smooth and flat, whereas the lingual face is very convex and may bear fine longitudinal ridges on the lower half. The cutting edges are smooth and appear biconvex due to medial curvature (Fig. 4g), and the edges end well before the cusp base. A small node or short ridge may occur near the crown base, well separated from the main cutting edge, on one or both sides of the main cusp. A single pair of very small, triangular lateral cusplets flanks the main cusp (Fig. 4h). When present, the short basal ridge is closely connected with the lateral cusplet (Fig. 4j). The root is bilobate with a large lingual boss that is bisected by a deep nutritive groove, and the thin dental band is impressed (Fig. 4f, g, i). Root lobes are elongated but of equal length, although the distal lobe may be slightly wider. Root height is roughly one-third (30\%) of the total tooth height.

Third lower anterior teeth. These teeth (Fig. 4k-n) are very similar to those of the second lower anterior file. They can be distinguished by their less convex cutting edges and root with a more elongated and narrower mesial lobe compared to the distal lobe (Fig. 4l, m).

Fourth lower anterior teeth. The main cusp is erect and slightly curved distally and has a sigmoidal profile (Fig. $4 \mathrm{p}-$ r). The cutting edges are smooth and convex apically but otherwise subparallel (Fig. 4r), nearly reaching the crown foot. The labial face is weakly convex and smooth, whereas the lingual face is very convex and only occasionally bears faint longitudinal ridges. A very convex ridge or small denticle, well separated from the main cutting edge, may occur on one or both sides of the cusp base (Fig. 4t). A single pair of broadly triangular cusplets flanks the main cusp. The lingual dental band is impressed. The lingual boss is indistinct, bisected by a thin nutritive groove (Fig. 4s, q). The bilobate root has a very elongated and narrow mesial lobe and very short, rounded distal lobe (Fig. 4q, r). Root height represents $30 \%$ (one-third) of the total tooth height. Teeth from this file are somewhat similar to the third upper anterior tooth, but they differ in that the main cusp is rather erect and has an obvious distal curvature (Fig. 4r). In contrast, the third upper anterior tooth has a highly distally inclined cusp that exhibits distinctive mesial curvature (i.e., Fig. 31, m).

Lower lateral teeth. In general, the main cusp is broadbased but sharply tapering, vertical to very slightly distally inclined, and flat to weakly sigmoidal in profile (Fig. $4 \mathrm{u}-\mathrm{w}$ ). The labial face is smooth and flat to very weakly convex, but the lingual face is convex and may bear faint vertical ridges on the lower half. The cutting edges are smooth and sharp and extend to the very base of the main cusp (Fig. 4w). The mesial and distal cutting edges are usually straight, but some teeth exhibit a mesial edge that is somewhat concave. The base of the cutting edge may be smooth and continuous or punctuated by one (rarely two) rounded-to-pointed denticle (or denticles; Fig. 4y). The main cusp is generally flanked by a single pair of tall, triangular, sharply pointed lateral cusplets (Fig. 4v, w), but an inconspicuous second cusplet may occur on one or both sides of the crown. The dental band is thin and impressed. The bilobate root bears a conspicuous boss that is bisected by a deep nutritive groove (Fig. 4v, x). The lobes are divergent, roughly of equal length, and separated by a V-shaped interlobe area, and their ends may be rounded or pointed (Fig. 4v, w). Root width is approximately two-thirds of the total tooth height.

Teeth within the first few lateral files have a slightly wider mesial lobe compared to the distal lobe (Fig. 4v, w). Other lateral teeth have more equidimensional root lobes and are difficult to place into a specific file. Within our sample of lower lateral teeth, it appears that the crown decreases in size and becomes slightly distally inclined towards the commissure. Lower lateral teeth are distinguished from upper lateral teeth in having erect main cusps as opposed to conspicuously distally inclined ones, and root lobes are less robust.

Lower posterior teeth. The lower posterior teeth are similar to the lower lateral teeth, but they are significantly smaller in size and have a much shorter main cusp (Fig. 4z-ad). The total root width is greater than the overall tooth height, the latter of which does not exceed $7 \mathrm{~mm}$ (Fig. 4aa, ab). No denticulations are present on any of the lower posterior teeth observed.

\section{Remarks}

Mennerotodus mackayi sp. nov. differs from the type species, Mennerotodus glueckmani (including the subspecies $M . g$. 
glueckmani and M. g. usunbassi), by anterior teeth having a maximum height of only $2.4 \mathrm{~cm}$ and there being only a single pair of lateral cusplets on upper and lower lateral teeth. In contrast, M. glueckmani anterior teeth can reach up to $7 \mathrm{~cm}$ in height, and upper and lower lateral teeth have two pairs of lateral cusplets. Of the two M. glueckmani boktensis teeth illustrated by Zhelezko and Kozlov (1999), the lower lateral tooth (pl. 6.3) has two pairs of lateral cusplets, and the mesial and distal cusplets of the upper left lateral tooth (pl. 6.4) are broad and appear to be serrated. These features contrast with the single pair of cusplets on M. mackayi sp. nov. lower and upper lateral teeth. The upper right lateral Mennerotodus sp. tooth illustrated by Dutheil et al. (2006, pl. 2.3) differs from all available $M$. mackayi sp. nov. upper lateral teeth in that the mesial cusplet appears serrated (rather than denticulation occurring at the base of the main cusp, medial to the lateral cusplet). The crown of M. mackayi sp. nov. appears to be more gracile and root lobes more elongated than on $M$. glueckmani, The crown and root of M. mackayi sp. nov. are more gracile than those of $M$. glueckmani usunbassi, and the crown is also straighter.

Three other lamniform taxa occur within the Clayton Formation that could be confused with Mennerotodus mackayi sp. nov., namely Palaeohypotodus rutoti (Winkler, 1874), Odontaspis substriata (Stromer, 1910), and Striatolamia cederstroemi Siverson, 1995. One specimen of $P$. rutoti (MMNS 8578) observed from Arkansas bears lateral denticulation similar to that on Mennerotodus mackayi sp. nov. teeth. However, Palaeohypotodus is easily distinguished from Mennerotodus by having teeth that are generally broader; lateral teeth with a distinctively distally curved main cusp; cutting edges that are continuous to the crown foot on all jaw positions; and larger lateral cusplets, of which there can be up to three pairs. Additionally, the secondary/tertiary cusplets on Palaeohypotodus teeth are conspicuously located on the labial face of the crown, not adjacent to the primary/secondary pair, and there are short longitudinal ridges at the labial crown foot (particularly obvious on smaller specimens). Lastly, M. mackayi sp. nov. teeth apparently do not reach the large size of Palaeohypotodus teeth (up to $3 \mathrm{~cm}$ in total tooth height).

The teeth of Odontaspis substriata differ from M. mackayi sp. nov. in having anterior teeth with two pairs of very tall and needlelike lateral cusplets and lateral teeth with three pairs of cusplets. In addition, the lingual faces of the main cusp and lateral cusplets of the substriata morphology bear very strong lingual ornamentation. The ornamentation on the main cusp varies depending on tooth size, with smaller teeth bearing ridges nearly to the lingual apex, whereas on larger teeth the ornamentation is only located on the lower half of the crown. On those teeth where ridges are not obvious on the main cusp, ornamentation is visible on the lingual face of the lateral cusplets. With very few exceptions, crown enameloid of Mennerotodus mackayi sp. nov. is smooth, and only rarely were extremely weak longitudinal ridges observed. In addi- tion, the lateral cusplets of $M$. mackayi sp. nov. are diminutive compared to those of $O$. substriata, and development of a second lateral cusplet (albeit diminutive) was very rarely observed. Lastly, the Odontaspis teeth never have the denticulation as observed on Mennerotodus.

Although tooth crowns of Striatolamia cederstroemi are smooth, this taxon is easily distinguished from M. mackayi sp. nov. in that the mesial and distal sides of the crown are drawn out into elongated shoulders or, more often, bear a very low, broad, weakly convex cusplet that is poorly differentiated from the main cusp. Our sample size of $S$. cederstroemi was relatively small $(n=35)$, but none of the specimens we examined bear denticulation as observed on $M$. mackayi sp. nov.

\section{Mennerotodus parmleyi sp. nov.}

LSID urn:lsid:zoobank.org:act:36F949AD-0166-453CAEB9-5805B7E9A141

1984 Odontaspis hopei, Westgate, p. 358, fig. 3a. 2003 Carcharias accutissima, Parmley and Cicimurri, fig. $3 \mathrm{e}$.

2003 Carcharias acutissima, Parmley and Cicimurri, p. 160161.

2003 Carcharias hopei, Parmley and Cicimurri, p. 161-162, fig. 3f.

2019 Mennerotodus sp., Ebersole et al., p. 50, fig. 17.

\section{Etymology}

The species is named in honor of Dennis Parmley, retired faculty member at Georgia College and State University, in recognition of his numerous contributions to our knowledge of the middle Eocene vertebrate faunas of central Georgia.

\section{Hypodigm}

SC2013.44.117 (paratype), first upper left anterior tooth (Fig. 5a-e); SC2013.44.119 (paratype), second upper left anterior tooth (Fig. 5 f-j); SC2013.44.122 (paratype), third upper left anterior tooth (Fig. 5k-o); SC2013.44.120 (paratype), left intermediate tooth (Fig. 5pt); SC2004.34.175 (holotype), first upper left lateral tooth (Fig. 5u-y); SC2013.44.128 (paratype), first lower right anterior tooth (Fig. 6a-e); SC2013.44.130 (paratype), second lower left anterior tooth (Fig. 6f-j); SC2013.44.132 (paratype), third lower right anterior tooth (Fig. 6k-o); SC2004.34.182 (paratype), fourth lower left anterior tooth (Fig. 6p-t); SC2013.44.157 (paratype), first lower left lateral tooth (Fig. 6u-y); SC2004.34.181 (paratype), lower right posterior tooth (Fig. 6a-ad). 


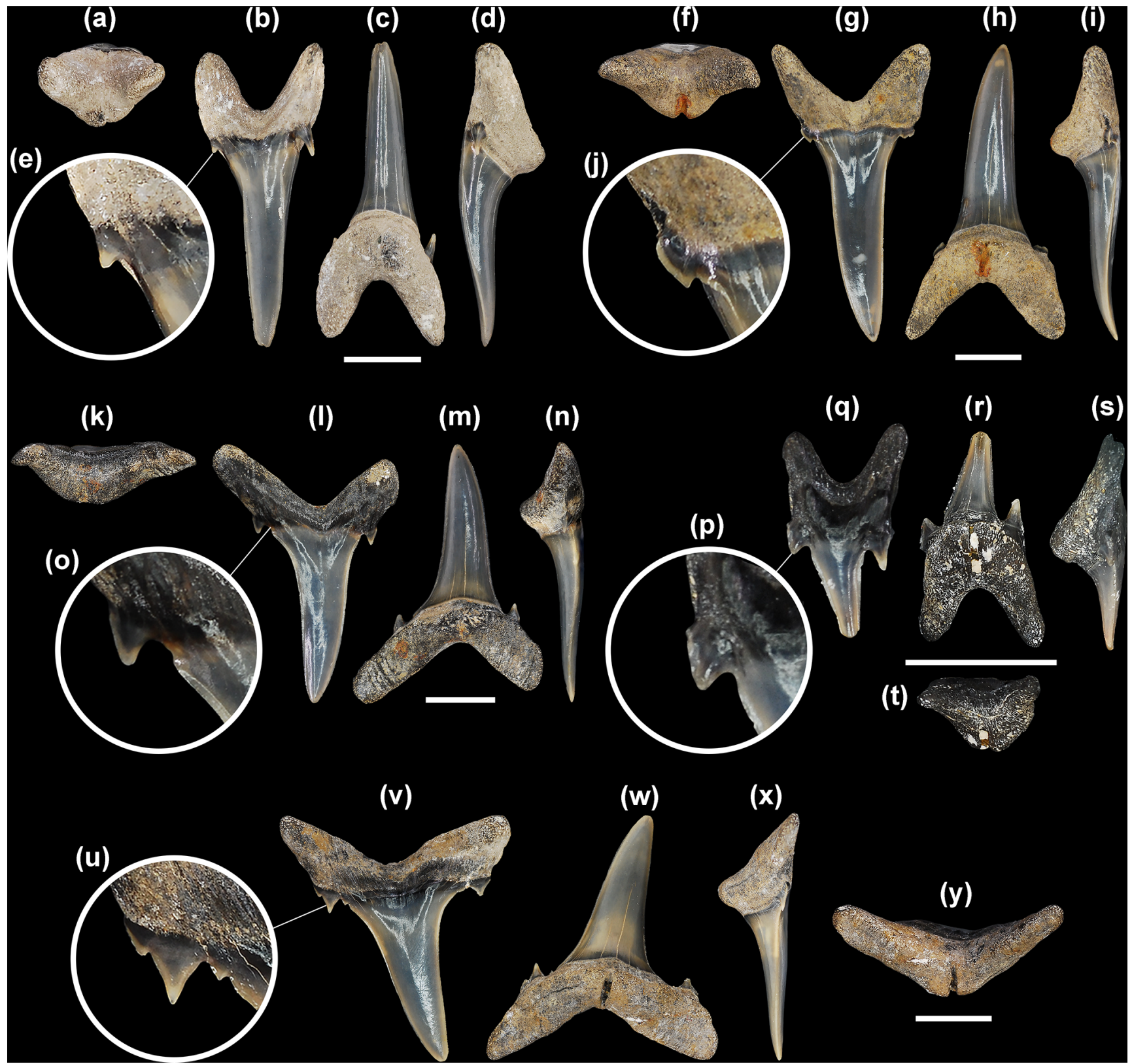

Figure 5. Mennerotodus parmleyi sp. nov. upper-dentition hypodigm, Eocene (Bartonian) Clinchfield Formation, Hardie Mine, Wilkinson County, Georgia, USA. (a-e) SC2013.44.117, first upper left anterior tooth (paratype). (a) Basal view. (b) Labial view. (c) Lingual view. (d) Mesial view. (e) Close-up of distal cusplet. (f-j) SC2013.44.119, second upper left anterior tooth (paratype). (f) Basal view. (g) Labial view. (h) Lingual view. (i) Mesial view. (j) Close-up of mesial cusplet. (k-o) SC2013.44.122, third upper left anterior tooth (paratype). (k) Basal view. (l) Labial view. (m) Lingual view. (n) Mesial view. (o) Close-up of mesial cusplet. (p-t) SC2013.44.120, upper left intermediate tooth (paratype). (p) Close-up of mesial cusplet. (q) Labial view. (r) Lingual view. (s) Mesial view. (t) Basal view. (u-y) SC2004.34.175, upper left lateral tooth (holotype). (u) Close-up of mesial denticle and cusplets. (v) Labial view. (w) Lingual view. (x) Mesial view. (y) Basal view. Labial at top in (a), (f), (k), (t), and (y). Scale bars $=5 \mathrm{~mm}$. 


\section{Referred specimens}

SC2004.34.17, second lower left anterior tooth; SC2004.34.18, third upper left anterior tooth; SC2004.34.19, upper left lateral tooth; SC2004.34.20, upper right lateral tooth; SC2004.34.21, first upper right lateral tooth; SC2004.34.22, upper right lateral tooth; SC2004.34.23, first upper right lateral tooth; SC2004.34.24, upper left lateral tooth; SC2004.34.25, lateral teeth (seven specimens); SC2004.34.26, upper lateral teeth (17 specimens); SC2004.34.27, unassigned teeth (two specimens); SC2004.34.28, upper lateral teeth (two specimens); SC2004.34.29, lower lateral tooth; SC2004.34.30, anterior teeth (27 specimens); SC2004.34.31, second upper right anterior tooth; SC2004.34.32, anterior tooth; SC2004.34.33, third upper right anterior tooth; SC2004.34.34, upper anterior teeth (13 specimens); SC2004.34.35, upper left lateral tooth; SC2004.34.36, upper lateral teeth (20 specimens); SC2004.34.37, small anterior teeth (eight specimens); SC2004.34.38, upper right lateral teeth (two specimens); SC2004.34.39, first upper left anterior tooth; SC2004.34.40, first lower anterior teeth (two specimens); SC2004.34.176, second lower left lateral tooth; SC2004.34.177, fourth upper left lateral tooth; SC2004.34.178, second? upper left lateral tooth; SC2004.34.179, third? upper right lateral tooth; SC2004.34.180, seventh? upper right lateral; SC2013.44.78, fourth? lower left anterior tooth; SC2004.34.186, lower lateral teeth (23 specimens); SC2013.44.117, first upper left anterior tooth; SC2013.44.118, first upper anterior teeth (12 specimens); SC2013.44.123, upper left lateral tooth; SC2013.44.124, upper lateral teeth (10 specimens); SC2013.44.125, second upper right lateral tooth; SC2013.44.126, first upper right lateral tooth; SC2013.44.127, first upper right lateral tooth; SC2013.44.129, first lower anterior teeth (two specimens); SC2013.44.131, lower anterior teeth (three specimens); SC2013.44.133, lower right lateral tooth; SC2013.44.134, lower right lateral tooth; SC2013.44.135, lower lateral teeth (20 specimens); SC2013.44.136, anterior teeth (six specimens); SC2013.44.137, third upper anterior teeth (two specimens; SC2013.44.138, incomplete anterolateral teeth (three specimens); SC2013.44.139, upper left lateral teeth (two specimens); SC2013.44.140, lateral teeth (14 specimens); SC2013.44.141, second upper left anterior tooth; SC2013.44.142, pathological tooth; SC2013.44.143, teeth from various jaw positions (229 specimens); SC2013.44.151, ablated teeth from various jaw positions (183 specimens).

\section{Type stratum}

Riggins Mill Member, Clinchfield Formation, middle Eocene (Bartonian Stage), calcareous nannofossil zone NP17 (Fig. 2b).

\section{Type locality}

Hardie Mine (reclaimed; $32.90027,-83.36499 ; 32^{\circ} 54^{\prime} 1^{\prime \prime} \mathrm{N}$, $83^{\circ} 21^{\prime} 54^{\prime \prime} \mathrm{W}$ ), near Gordon, Wilkinson County, Georgia, USA (Fig. 2a).

\section{Description}

First upper anterior teeth. These small teeth, which do not exceed $21 \mathrm{~mm}$ in total height, are slightly asymmetrical in labial view (Fig. 5b). The main cusp is very narrow, is slightly distally inclined, and has a sigmoidal profile (Fig. 5c, d). Mesial and distal cutting edges are sharp, smooth, and subparallel but never reach the base of the main cusp. There may be a minuscule tubercle or very short and sharp ridge at the very base of the main cusp, well separated from the main cutting edge (Fig. 5e). A single pair of short, conical cusplets is located at the crown foot (Fig. 5a). The labial face of the main cusp is smooth, is flat apically but weakly convex on its lower half, and in distal view appears to have a slight twist. In contrast, the lingual face is very convex and may bear faint longitudinal ridges on the lower half. The root is bilobate and has a large lingual boss that is bisected by an elongate and deep nutritive groove (Fig. 5a, c, d). The lingual dental band at the crown foot is conspicuous and sometimes deeply impressed. Root lobes are rather short and may be cylindrical or mesiodistally compressed. The distal lobe is more elongated and more obviously angled away from the nutritive groove (Fig. 5b, c).

Second upper anterior teeth. The largest specimen measures $33 \mathrm{~mm}$ in total height. The main cusp is tall and narrow, more triangular in appearance than the main cusp of the first anterior tooth, and slightly distally inclined. Cutting edges are biconvex apically but otherwise subparallel (Fig. 5g, h), and they do not reach the cusp base (Fig. 5j). The labial face is smooth and flat to very weakly convex, but the lingual face is very convex and may bear fine vertical ridges on the lower half. The main cusp is flanked by a single pair of cusplets, although a second diminutive cusplet was occasionally observed on the mesial side (Fig. 5g, h). Cusplets are conical to triangular, sharply pointed, and lingually curved. Conical cusplets lack cutting edges, but more triangular cusplets exhibit complete cutting edges. The lingual boss bears a thin nutritive groove, and the dental band may be impressed (Fig. 5f, h). Although root lobes are of nearly the same length, the mesial lobe is labiolingually thick, mesiodistally thin, and pointed basally, whereas the distal lobe is labiolingually thin, mesiodistally wide, and rounded basally (Fig. 5g, h).

Third upper anterior teeth. The largest specimen measures $32 \mathrm{~mm}$ in total height. Teeth from this position differ from those of the other anterior positions in having a main cusp that is distally directed, often mesially curving, and only weakly sigmoidal in profile (Fig. 51-n). In addition, root lobes are asymmetrically developed, with the mesial lobe 


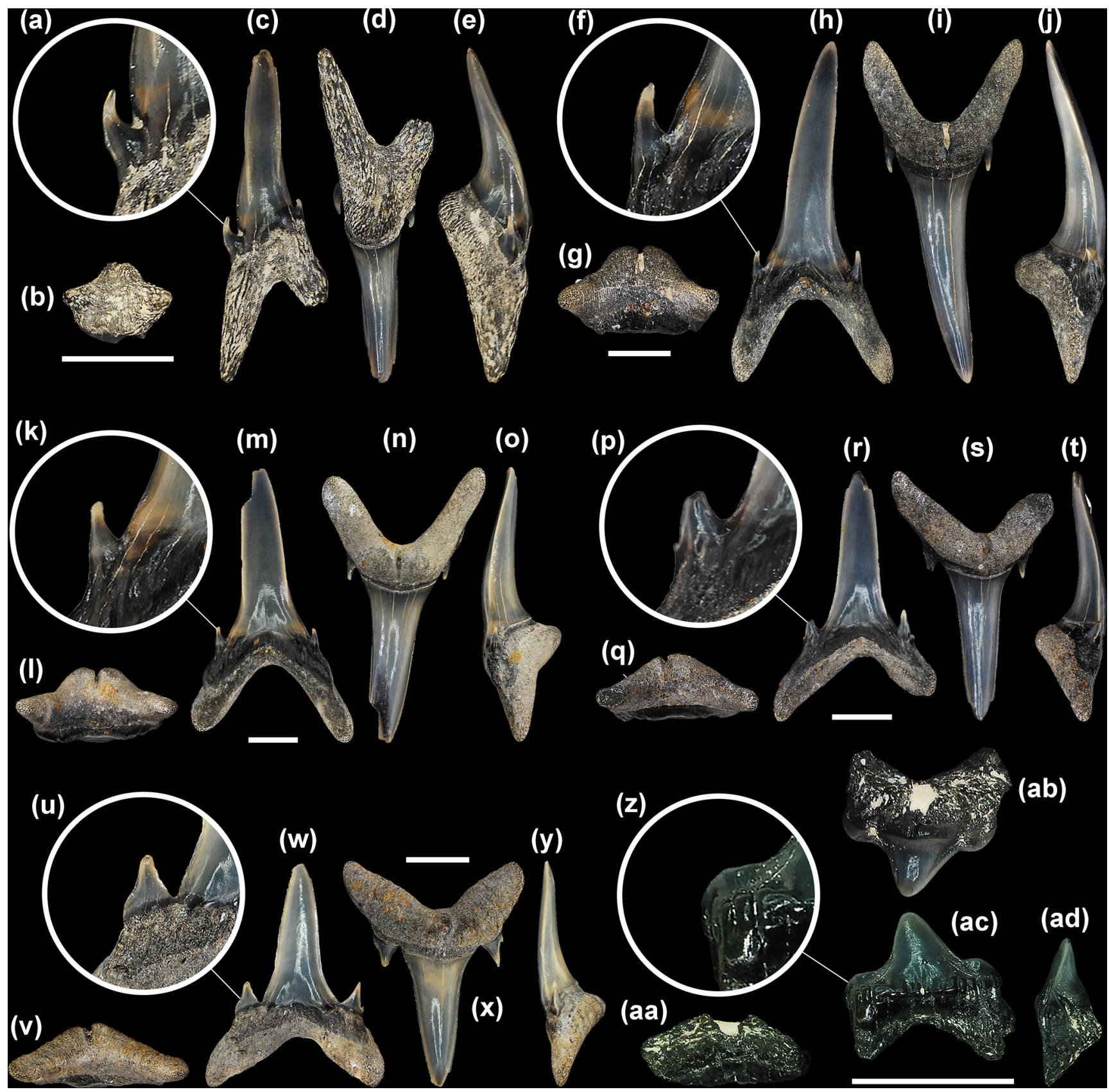

Figure 6. Mennerotodus parmleyi sp. nov. lower-dentition hypodigm, Eocene (Bartonian) Clinchfield Formation, Hardie Mine, Wilkinson County, Georgia, USA. (a-e) SC2013.44.128, first lower right anterior tooth (paratype). (a) Close-up of distal cusplet. (b) Basal view. (c) Labial view. (d) Lingual view. (e) Distal view. (f-j) SC2013.44.130, second lower left anterior tooth (paratype). (f) Close-up of mesial cusplet. (g) Basal view. (h) Labial view. i) Lingual view. (j) Mesial view. (k-o) SC2013.44.132, lower right anterior tooth (paratype). (k) Closeup of distal cusplet. (l) Basal view. (m) Labial view. (n) Lingual view. (o) Mesial view. (p-t) SC2004.34.182, fourth lower left anterior tooth (paratype). (p) Close-up of mesial cusplet. (q) Basal view. (r) Labial view. (s) Lingual view. (t) Mesial view. (u-y) SC2013.44.157, lower left lateral tooth (paratype). (u) Close-up of mesial cusplet. (v) Basal view. (w) Labial view. (x) Lingual view. (y) Distal view. (zad) SC2004.34.181, lower right posterior tooth (paratype). (z) Close-up of distal cusplet. (aa) Basal view. (ab) Lingual view. (ac) Labial view. (ad) Mesial view. Labial at bottom in (b), (g), (l), (q), (v), and (aa). Scale bars $=5 \mathrm{~mm}$. 
being much more elongated than the distal one, as well as sharply divergent from the nutritive groove (Fig. 51, m). The labial face of the main cusp is smooth and very nearly flat, whereas the lingual face is convex and may bear very fine and discontinuous vertical ridges on the lower half. The cutting edges are smooth and sharp and extend to the crown foot (Fig. 5o). The base of the cutting edge may be continuous or denticulated. Lateral cusplets are small but broad, more labiolingually compressed, and with a more conspicuous cutting edge than those of the first two anterior files (Fig. 51, m). The lingual dental band is conspicuous and may be impressed, and although the nutritive groove is elongated, the boss is less robust than is seen on the other two anterior files (Fig. 5k, m, n).

Intermediate teeth. A single left intermediate tooth is represented. It measures nearly $8 \mathrm{~mm}$ in total height and $4 \mathrm{~mm}$ in width. The crown consists of a rather short and narrow main cusp that is straight and flat in profile (not sigmoid) and slightly distally inclined (Fig. 5q-s). There is a single pair of lateral cusplets, with the distal cusplet being larger (Fig. 5q). The labial face of the main cusp is flat, whereas the lingual face is very convex, and the cutting edge is continuous from the apex to the lateral cusplets. The root is bilobate with short (the distal lobe is longer), divergent lobes having rounded ends (Fig. 5r). A large lingual boss is bisected by an elongated nutritive groove (Fig. $5 \mathrm{r}-\mathrm{t}$ ).

Upper lateral teeth. Upper lateral teeth can be differentiated from the anterior teeth in that the main cusp is labiolingually thinner, flat, and distally inclined, and the base is broader (Fig. $5 \mathrm{v}-\mathrm{x}$ ). Root lobes are shorter but wider, and they are more strongly divergent. The first few upper lateral tooth files are identified by their more elongated, narrower, and basally pointed mesial lobe, compared to the short, wide, rounded distal lobe (Fig. 5v, w). Other lateral teeth have more equidimensional root lobes and are difficult to place into a specific file. Within our sample of upper lateral teeth, it appears that the crown decreases in size but becomes more strongly distally inclined towards the commissure.

The main cusp of lateral teeth is broad-based but sharply tapering, distally inclined, and straight in profile view. The labial face is smooth and flat to very weakly convex, but the lingual face is convex (although not as strongly as anterior teeth) and may bear fine vertical ridges on the lower half. The cutting edges are smooth and sharp and extend to the very base of the main cusp. The mesial and distal cutting edges may be straight, but more commonly the upper part of the main cusp appears distally curving because the mesial edge is convex and the distal edge straight to concave (Fig. 5v). The base of the cutting edge may be continuous and sharp or sometimes punctuated by one or more rounded-to-pointed denticles (Fig. 5u). The main cusp is usually flanked by a single pair of low, broadly triangular lateral cusplets (Fig. 5v, w), but occasionally a poorly developed second pair was observed (Fig. 5u). The lingual face of each cusplet is more convex than the labial face, and the cutting edge is complete from the mesial to distal side. An elongated and deep lingual nutritive groove divides the root into roughly equidimensional, subrectangular lobes with pointed ends (Fig. $5 \mathrm{w}$, y). The interlobe area is V-shaped, and many teeth have a labiobasal depression at the crown base. The lingual dental band is impressed, but the root boss is less distinctive than on anterior teeth (Fig. 5y). Root width is nearly equal to total tooth height.

Upper posterior teeth. No upper posterior teeth have been identified in the sample.

First lower anterior teeth. Teeth from this file are not known to exceed $13 \mathrm{~mm}$ in total height. The main cusp is very narrow and may be straight to weakly curved distally, and it is inclined towards the symphysis (Fig. 6c, d). The labial face is weakly convex and smooth, whereas the lingual face is very convex (Fig. 6e). Cutting edges are smooth, sharp, and subparallel and do not reach the crown foot. A minuscule tubercle or very short and sharp edge, well separated from the main cutting edge, may occur. A single pair of lateral cusplets flanks the main cusp, and in labial view the mesial cusplet appears to be located higher on the tooth than the distal cusplet (Fig. 6c, d). Cusplets are small, conical, sharply pointed, and lingually curving (Fig. 6a). The root is laterally compressed and bilobate with a much shorter mesial lobe, and the large lingual boss is bisected by a nutritive groove (Fig. 6b-e). Root height is equal to crown height.

Second lower anterior teeth. Teeth in this position are symmetrical and reach at least $32 \mathrm{~mm}$ in total height. The main cusp is tall, narrow, and erect and has a sigmoidal profile (Fig. $6 \mathrm{~h}-\mathrm{j}$ ). The labial face is smooth and flat apically but may be more convex near the base, whereas the lingual face is very convex (Fig. 6j) and may bear fine vertical ridges on the lower half. The cutting edges are subparallel and appear biconvex due to medial curvature near their base, and the edges end well before the cusp base (Fig. 6h, i). A single pair of conical, sharply pointed, and lingually curved lateral cusplets is present (Fig. 6f). The root is bilobate with a large lingual boss that is bisected by a deep nutritive groove, and the dental band is wide and impressed (Fig. 6g, i, j). Root lobes are elongated and of equal length, although the mesial lobe may be slightly wider (Fig. 6h, i). Root height is roughly one-third (30\%) of the total tooth height.

Third lower anterior teeth. These teeth (Fig. 6k-o) are essentially the same as those of the second anterior file. However, they can be distinguished by their more divergent root lobes and an elongated and narrower mesial root lobe compared to the distal lobe (Fig. 6m, n).

Fourth lower anterior teeth. Teeth in this file (Fig. 6p-t) are morphologically similar to those in the third upper anterior file (i.e., Fig. 5k-o), but they differ in that the main cusp is distally inclined but not mesially curving and both root lobes are slightly more elongated (Fig. 6r, s). Cutting edges very nearly reach the crown foot. A single pair of lateral cusplets flanks the main cusp, and these cusplets bear conspicuous cutting edges and are broader than those on the 
more proximal anterior teeth (Fig. 6p-s). The distal root lobe is shorter, wider, and more rounded than the mesial lobe, which is elongated and pointed at the end (Fig. 6r, s). The root lobes of teeth from this file are more divergent than on the third lower anterior file (compare Fig. 6m to Fig. 6r).

Lower lateral teeth. Lower lateral teeth can be differentiated from the anterior teeth in that the crown is shorter, labiolingually thinner, and rather flat and cutting edges extend to the crown foot (Fig. $6 \mathrm{w}-\mathrm{y}$ ). Root lobes are shorter but wider, and they are more widely separated (Fig. 6x). The root lobes in the first few lower lateral files have a slightly shorter and wider mesial lobe compared to the distal lobe, but other lateral teeth have more equidimensional root lobes and are difficult to place into a specific file. Within our sample of lower lateral teeth, it appears that the crown decreases in size and becomes slightly distally inclined towards the commissure. Lower lateral teeth are distinguished from upper lateral teeth by having erect main cusps as opposed to conspicuously distally inclined ones, and root lobes are shorter, lower, and more pointed (compare Fig. 6w to Fig. 5v).

In general, the main cusp is broad-based but sharply tapering, vertical to slightly distally inclined, and virtually flat with little to no lingual curvature. The labial face is smooth and flat to very weakly convex, but the lingual face is convex (although not as strongly as on anterior teeth) and may bear fine vertical ridges on the lower half. The cutting edges are smooth and sharp and extend to the very base of the main cusp (Fig. 6u). The mesial and distal cutting edges are usually straight, but some teeth exhibit a mesial edge that is convex on its upper part. The base of the cutting edge may be smooth and continuous or punctuated by one or more rounded-topointed denticles. The main cusp is flanked by a single pair of low, broadly triangular lateral cusplets (Fig. 6w, v), but a poorly developed second pair on one or both sides sometimes occurs. The lingual face of the cusplet is more convex than the labial face, and the cutting edge is complete from the mesial to distal side. An elongated and deep lingual nutritive groove divides the root into low, roughly equidimensional lobes with rounded or pointed ends (Fig. $6 \mathrm{w}, \mathrm{x}$ ). The lingual dental band is impressed, but the root boss is less distinctive than on anterior teeth (Fig. 6v, y). Root width nearly equals total tooth height.

Lower posterior teeth. A single lower posterior tooth measures $5 \mathrm{~mm}$ in height and $5.5 \mathrm{~mm}$ in width. The crown is very low, broadly triangular, bluntly pointed, and slightly distally directed (Fig. 6ab, ac). There is a single pair of rather large but low, broad, and blunt lateral cusplets (Fig. 6z, ac). The labial crown face is flat and bears heavy basal vertical wrinkling. The root is bilobate and bisected by a lingual nutritive groove (Fig. 6aa, ac). Lobes are short, wide, and basally pointed, separated by a V-shaped interlobe area (Fig. 6ab, ac). Posterior teeth having a very low, convex crown that is poorly differentiated from the lateral cusplets, like those occurring near the jaw commissure of extant Carcharias taurus, are unknown for M. parmleyi sp. nov.

\section{Remarks}

Mennerotodus parmleyi sp. nov. differs from $M$. glueckmani (including $M$. g. glueckmani and $M$. g. usunbassi) in having anterior teeth that do not exceed $3.5 \mathrm{~cm}$ in total height and in lateral teeth generally having only a single pair of lateral cusplets (on rare occasions there is a second diminutive cusplet on one or both sides of the main cusp). In contrast, anterior M. glueckmani teeth can attain $7 \mathrm{~cm}$ in total height and lateral teeth have two pairs of mesial and distal cusplets. The lower lateral tooth of M. g. boktensis illustrated by Zhelezko (1994, pl. 6.3) has two pairs of lateral cusplets, and the mesial and distal cusplets of the upper left lateral tooth (pl. 6.4) are broad and appear to be serrated. The crown of $M$. parmleyi sp. nov. is less curved than that of $M$. glueckmani usunbassi, and the root lobes are more elongated than on the teeth of both $M . g$. glueckmani and M. g. usunbassi.

Mennerotodus parmleyi sp. nov. attains a larger overall size than M. mackayi sp. nov. (i.e., anterior teeth reach $3.3 \mathrm{~cm}$ in height vs. $2.4 \mathrm{~cm}$ ). When present, denticulation on $M$. parmleyi sp. nov. is more conspicuous and more extensively developed than on M. mackayi sp. nov. In addition, upper lateral teeth of M. parmleyi sp. nov. are as wide (root width) as they are tall (total tooth height), whereas equivalent teeth of $M$. mackayi sp. nov. are taller than they are wide. Also, lingual faces of $M$. parmleyi sp. nov. teeth may bear fine longitudinal ridges, but crown enameloid of $M$. mackayi sp. nov. is generally smooth. In nearly all tooth positions, the ratio of crown height to root height is greater on M. parmleyi sp. nov. teeth than on M. mackayi sp. nov.

The upper lateral Mennerotodus sp. tooth illustrated by Dutheil et al. (2006, pl. 2.3) differs from all available $M$. parmleyi sp. nov. upper lateral teeth in that the mesial cusplet is serrated, as opposed to denticulation occurring at the base of the main cusp (medial to the cusplet).

In their report on the fossil sharks from the Clinchfield Formation in central Georgia, Parmley and Cicimurri (2003) reported several Carcharias-like tooth morphologies that they identified as Carcharias acutissimus, C. hopei (=Hypotodus verticalis; Agassiz, 1843), C. koerti (=Brachycarcharias koerti; Stromer, 1910), and Striatolamia cf. macrota (Agassiz, 1843). The lateral teeth they identified as $C$. koerti are distinctive for their large size, broadly triangular main cusp, and two pairs of robust and diverging lateral cusplets. We believe that this morphology is more appropriately identified as Brachycarcharias twiggsensis (Case, 1981), and this taxon will not be confused with Mennerotodus parmleyi sp. nov. (also Ebersole et al., 2019).

Of the three remaining taxa, Parmley and Cicimurri (2003) differentiated Carcharias acutissimus from C. hopei based primarily on the presence or absence of lingual crown ornamentation. However, our examination of two $C$. taurus dentitions (SC86.62.6 and SC2000.120.6) showed that these features are variable and may not be taxonomically significant (also Applegate 1965; Purdy et al., 2001). Our evalu- 


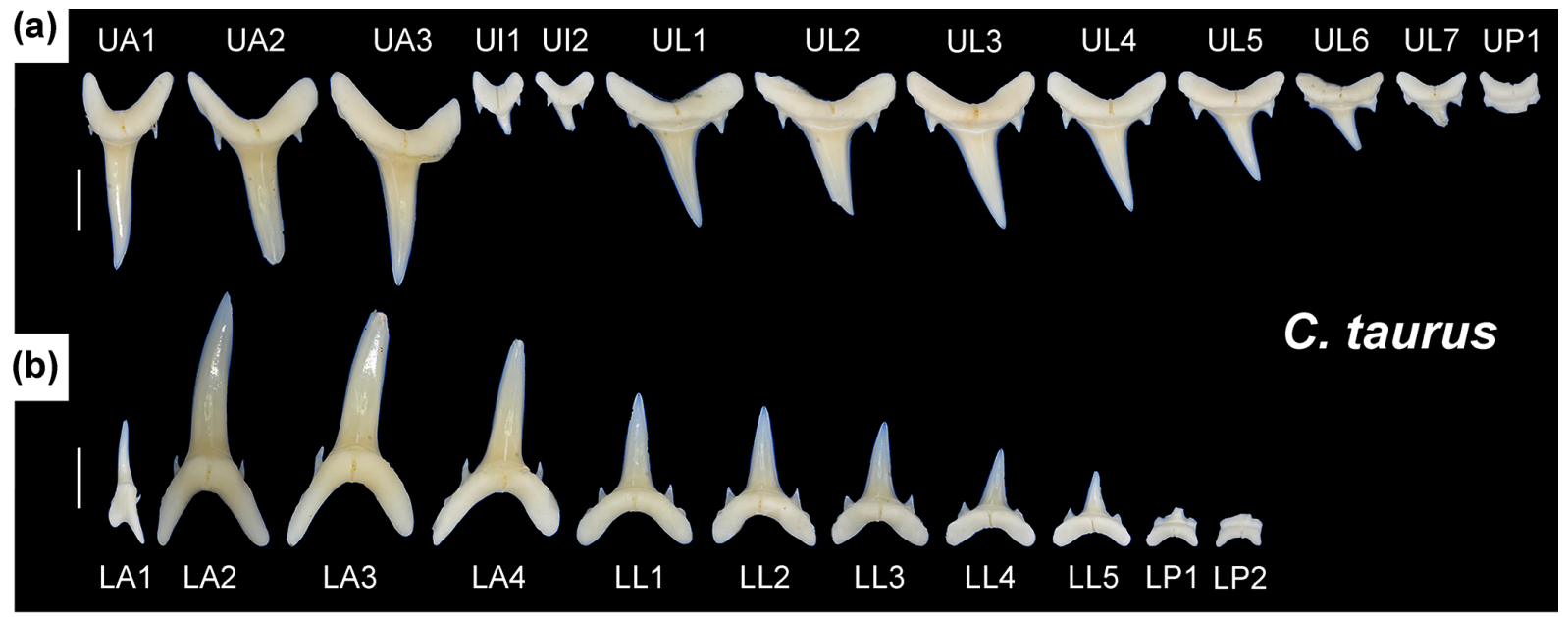

(c)
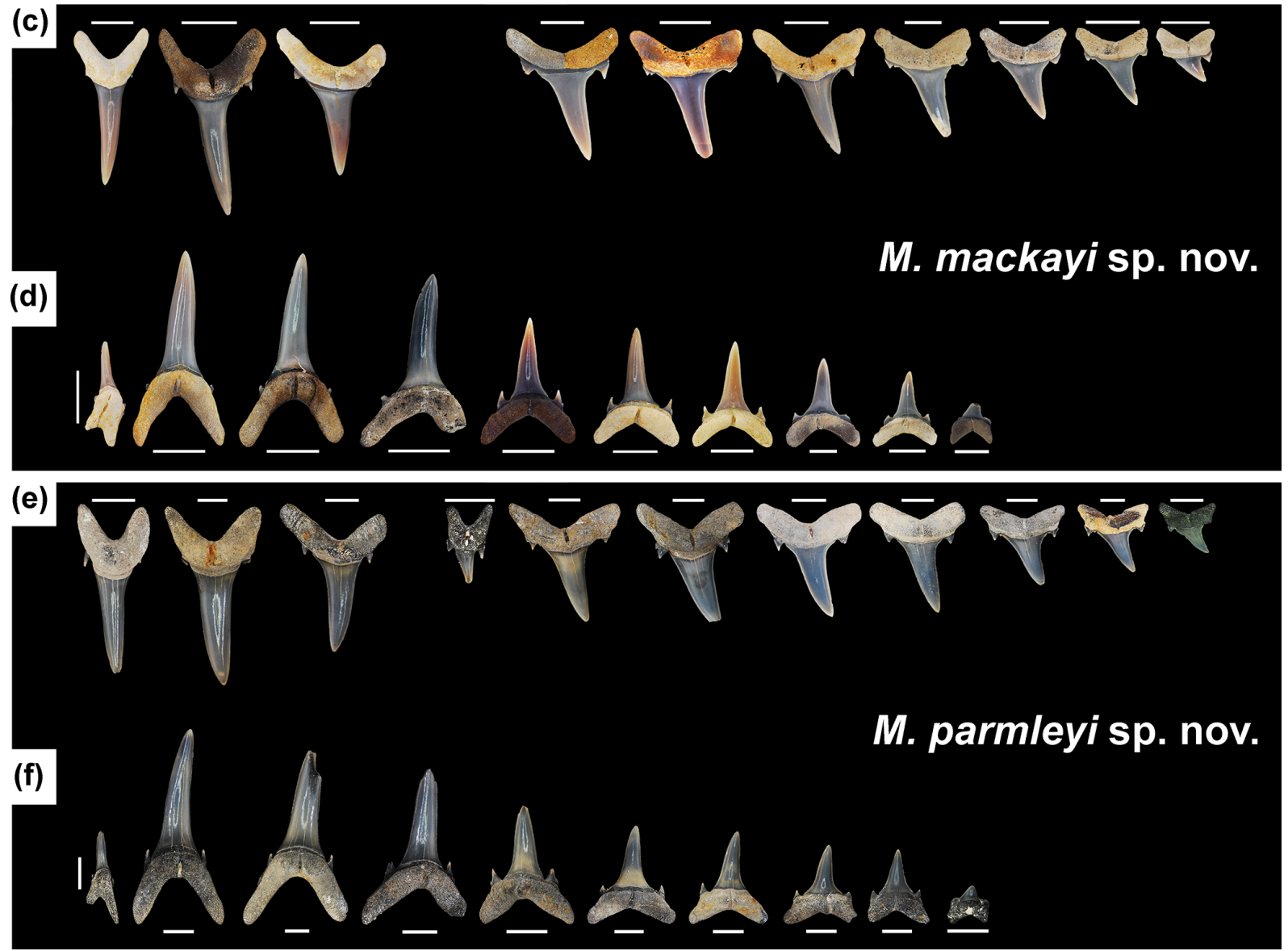

Figure 7. Lingual view of right dentitions of Carcharias taurus, Mennerotodus mackayi sp. nov., and Mennerotodus parmleyi sp. nov. (a-b) C. taurus, unnumbered specimen from Gordon Hubbell Collection, natural tooth set. (a) Upper dentition. (b) Lower dentition. (c-d) M. mackayi sp. nov., artificial tooth set. (c) M. mackayi sp. nov. upper dentition, from left to right: MSC 42411, paratype; MSC 42408, paratype; MSC 42413, paratype (reversed); MSC 42495; MSC 42718; MSC 42412, holotype; MSC 42421; MSC 42494; MSC 42497; MSC 42416 (reversed). (d) M. mackayi sp. nov. lower dentition, from left to right: MSC 42407, paratype; MSC 42405, paratype (reversed); MSC 42410, paratype; MSC 42406, paratype (reversed); MSC 42719 (reversed); MSC 42409, paratype; MSC 42500; MSC 42498; MSC 42501; MSC 42632. (e-f) M. parmleyi sp. nov., artificial tooth set. (e) M. parmleyi sp. nov. upper dentition, from left to right: SC2013.44.117, paratype; SC2013.44.119, paratype (reversed); SC2013.44.122, paratype (reversed); SC2013.44.120, paratype (reversed); SC2004.34.175, holotype (reversed); SC2004.34.178; SC2004.34.179; SC2004.34.177 (reversed); SC2013.44.1123 (reversed); SC2013.44.153; SC2004.34.38. (f) M. parmleyi sp. nov. lower dentition, from left to right: SC2013.44.128, paratype; SC2013.44.130, paratype; SC2013.44.132, paratype; SC2004.34.182, paratype; SC2013.44.157, paratype; SC2004.34.176 (reversed); SC2013.44.154; SC2013.44.155; SC2013.44.156; SC2004.34.181, paratype. Scale bars $=5 \mathrm{~mm}$. 
ation of the Clinchfield Formation odontaspidid teeth leads us to conclude that the material identified as C. acutissima and $C$. hopei by Parmley and Cicimurri (2003) is conspecific and represents variation within Mennerotodus parmleyi $\mathrm{sp}$. nov. This is corroborated by the fact that those authors noted (p. 161) that some of their $C$. hopei lateral teeth exhibited "serrations" between the cusplets and main cusp.

Parmley and Cicimurri (2003) described their Striatolamia cf. macrota tooth as having lingual crown ornamentation and cutting edges extending to the crown foot. Based on our reconstruction of the Mennerotodus parmleyi sp. nov. dentition, this tooth represents a very large (adult) M. parmleyi sp. nov. distally located anterior tooth. Anterior teeth of Striatolamia macrota that we examined in large samples from the Bartonian Tupelo Bay Formation of South Carolina (at SC) and Gosport Sand of Alabama (at MSC) show that the lingual crown ornamentation is very robust and extends to at least two-thirds of the crown height, and lateral cusplets are diminutive. Additionally, when compared to M. parmleyi sp. nov., lateral teeth of $S$. macrota have a broader crown with a less pointed apex, lateral cusplets (single pair) are broader and rounded (the distal cusplet being larger than the mesial one), and root lobes are shorter but broader. The single intermediate tooth we attribute to $M$. parmleyi sp. nov. is identical to intermediate teeth occurring on the upper jaws of the two C. taurus dentitions we examined (SC86.62.6 and SC2000.120.6). Of the two other lamniform sharks occurring within the Clinchfield Formation, the teeth of Macrorhizodus praecursor lack lateral cusplets and the teeth of Brachycarcharias twiggsensis are larger in overall size, have much broader crowns, and have much larger lateral cusplets (Case, 1981).

\section{Discussion}

Several extinct Eocene odontaspidid genera have teeth that may possess denticulation similar to that occurring on Mennerotodus, including Araloselachus, Borealotodus, Jaekelotodus, and Tobolamna. The late Eocene to middle Miocene Araloselachus was for a time considered to be synonymous with Carcharias (Cappetta and Nolf, 2005) but is now considered distinct and includes species that had previously been assigned to Carcharias (Glickman, 1964; De Schutter, 2011; Reinecke and Radwański, 2015; Szabó and Kocsis, 2016; Kent, 2018; Pollerspöck and Gille, 2018). Cappetta (2012) concluded that teeth of the two genera are distinct, and it appears that Araloselachus differs from Mennerotodus in having anterior teeth with convex labial faces. In contrast, Mennerotodus anterior teeth have flat labial faces, and all tooth positions may bear fine lingual longitudinal ridges. Crown enameloid is generally smooth on Araloselachus teeth, although some posterior teeth may bear basal longitudinal ridges on the labial face (De Schutter, 2011). Additionally, Glickman (1964) indicated that the main cusp of Ar- aloselachus is broader than that of Carcharias. We believe the term "broader" can be interpreted as the fact that on $A r$ aloselachus anterior teeth, the cutting edges are subparallel to the base of the main cusp, whereas Mennerotodus anterior teeth display conspicuous oblique heels at the base that slope towards the lateral cusplets. The neotype and paraneotype of A. vorax (Le Hon, 1871) as designated by De Schutter (2011) show this to be the case, as do specimens of A. cuspidatus (Agassiz, 1843) illustrated by Cappetta (2012, fig. 180, AG) and A. turgaensis Zhelezko, 1999, figured in Zhelezko and Kozlov (1999, pl. 3, 7-8).

Anterior teeth of the various species of Jaekelotodus are much more robust than those of Mennerotodus, and cutting edges are complete to the crown base (Zhelezko and Kozlov, 1999; Cappetta and Nolf, 2005; Van den Eeckhaut and De Schutter, 2009) on all tooth positions. Mennerotodus anterior teeth are very narrow, and cutting edges generally do not extend to the crown base. Lateral teeth of Jaekelotodus have rather broad and often conspicuously distally hooked main cusps, as opposed to inclined crowns that are straight to only weakly curved on Mennerotodus lateral teeth. Additionally, Jaekelotodus lateral cusplets are very diminutive compared to the large size of the main cusp (Zhelezko and Kozlov, 1999; Cappetta and Nolf, 2005; Van den Eeckhaut and De Schutter, 2009). Although Mennerotodus was originally placed within the family Jaekelotodontidae, Cappetta and Nolf (2005) concluded that there were no unique dental characteristics to support the validity of this group, and they placed genera like Jaekelotodus and Mennerotodus within Odontaspididae.

In a review of Eocene selachians from Russia, Malyskhina (2006b) placed two species of Tobolamna, T. laevinae Zhelezko and Kozlov, 1999, and T. tobolensis Zhelezko and Kozlov, 1999, in synonymy with Carcharias acutissimus (Agassiz, 1843). However, Cappetta (2012) considered the genus Tobolamna to be synonymous with Borealotodus.

We utilized the dentition of extant Carcharias taurus Rafinesque, 1810, to reconstruct the dentitions of the two new species of Mennerotodus described below. The anterior teeth of Mennerotodus differ from those of $C$. taurus in being less lingually curved and less sigmoidal in profile. The labial face of Mennerotodus teeth is virtually flat in all tooth positions, whereas it is convex on $C$. taurus. The root lobes of Mennerotodus teeth are wider and more rectangular in outline (evident on lateral teeth), their ends are more pointed, and the interlobe area is more angular compared to C. taurus, which has comparatively thinner and rounded lobes and a U-shaped interlobe area. Denticulation was not observed on teeth in any of the $C$. taurus dentitions we examined and has not been reported for this species (i.e., Applegate, 1965; Purdy et al., 2001; Lucifora et al., 2003). 

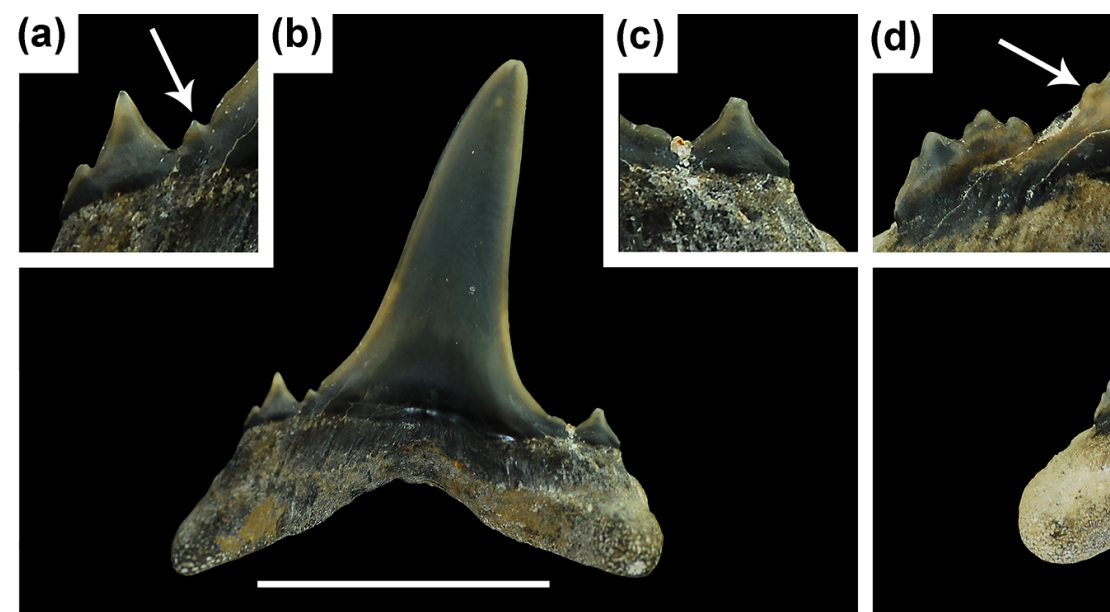

(e)
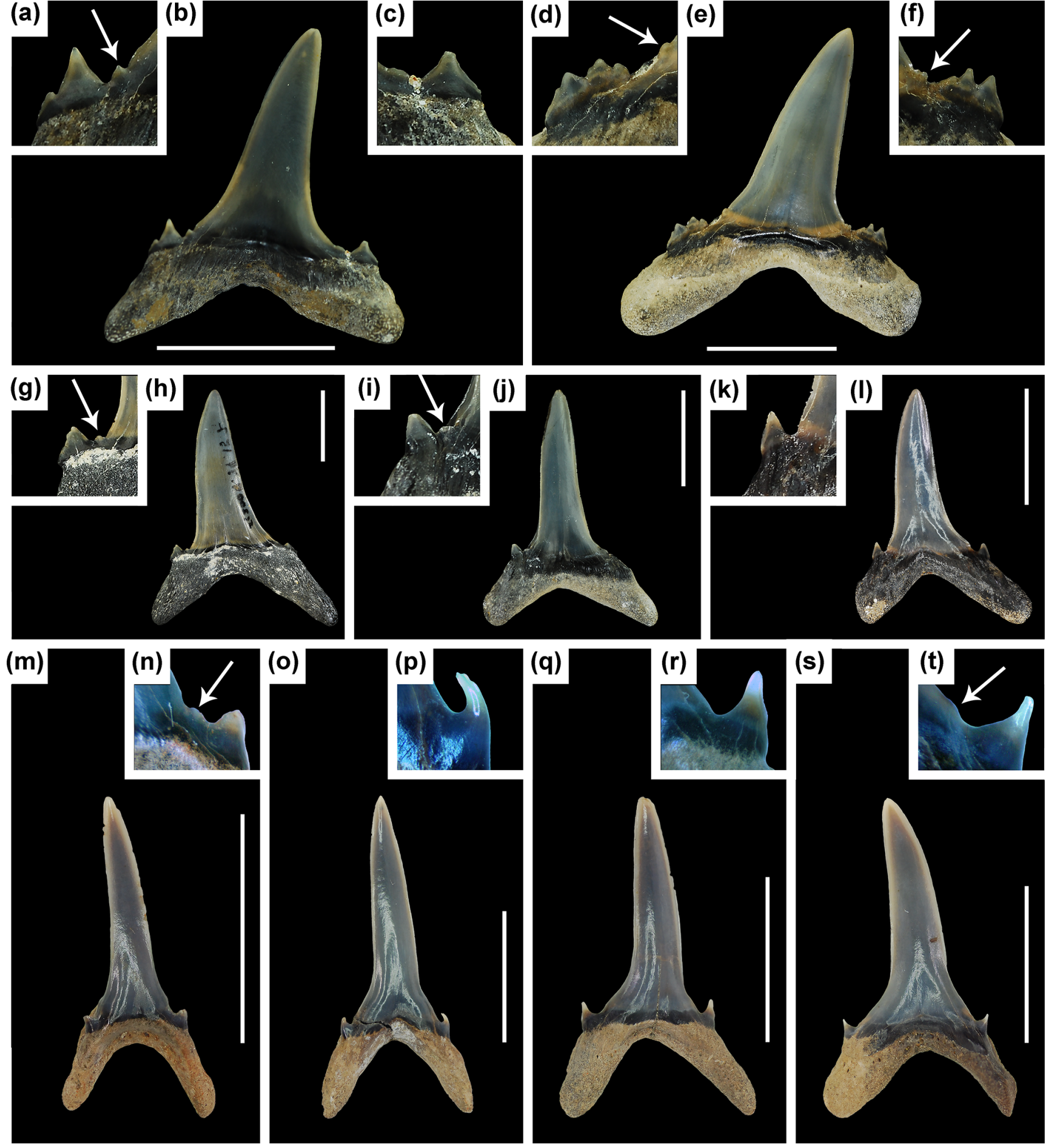

Figure 8. Ontogenetic variation in Mennerotodus. (a-l) Mennerotodus parmleyi sp. nov. teeth. (a-f) Upper lateral teeth in labial view. (ac) SC2004.34.175, left tooth, holotype, (reversed). (a) Close-up of mesial denticle and cusplets. (b) Whole tooth. (c) Close-up of distal cusplet. (d-f) SC2004.34.23, right tooth. (d) Close-up of mesial denticulations and cusplets. (e) Whole tooth. (f) Distal denticulations and cusplets. (g-l) Third upper anterior teeth in labial view. (g-h) SC2004.34.157, right tooth (reversed). (g) Close-up of distal denticle and cusplet. (h) Whole tooth. (i-j) SC2004.34.184, left tooth. (i) Close-up of distal denticle and cusplet. (j) Whole tooth. (k-l) SC2013.44.122, left tooth, paratype. (k) Close-up of distal cusplet. (l) Whole tooth. (m-t) Mennerotodus mackayi sp. nov. (m-p) Second lower anterior teeth in labial view. (m-n) MSC 42634, right tooth. (m) Whole tooth. (n) Close-up of mesial denticle and cusplet. (o-p) MSC 42633, right tooth. (o) Whole tooth. (p) Close-up of mesial denticle. (q-t) Third upper anterior teeth in labial view. (q-r) MSC 42635, left tooth (reversed). (q) Whole tooth. (r) Close-up of mesial cusplet. (s-t) MSC 42636, right tooth. (s) Whole tooth. (t) Close-up of mesial denticle and cusplet. Scale bars $=5 \mathrm{~mm}$. 


\subsection{Taxonomic issues among various similar genera}

As discussed above, Mennerotodus-type denticles can appear on teeth attributed to several different extinct genera, including Palaeohypotodus, Jaekelotodus, Araloselachus, Borealotodus, and Tobolamna. Palaeohypotodus and Jaekelotodus are easily distinguished from Mennerotodus, as they have broader main cusps, conspicuously hooked lateral teeth, diminutive cusplets compared to the size of the main cusp, and cutting edges that are continuous to the base of the main cusp in all tooth files, and many Palaeohypotodus teeth exhibit fine labial ornamentation at the crown foot. Unfortunately, the morphological criteria used to distinguish the various other genera have been poorly described and can be variable (e.g., teeth are described as being "broad").

With regard to Tobolamna, Malyshkina (2006a) considered some species assigned to this genus to be synonymous with Carcharias acutissimus, and Cappetta (2012) has synonymized the entire genus Tobolamna with Borealotodus. Although Araloselachus is primarily considered an Oligocene to middle Miocene taxon, at least one species ( $A$. turgaensis Zhelezko and Kozlov, 1999) has been reported from upper Eocene (Priabonian) strata. Several species now attributed to this genus were formerly placed within Carcharias (i.e., C. cuspidatus Agassiz, 1843, and C. vorax Le Hon, 1871), and in fact $C$. taurus was used as the basis for reconstructing dentitions for these species (i.e., De Schutter, 2011). One curious feature of at least some Araloselachus teeth is that lateral cusplets can be serrated or pectinate, as for example A. cuspidatus, A. turgaensis, and A. vorax (Zhelezko and Kozlov, 1999; De Schutter, 2011; Cappetta, 2012). If this morphology is taxonomically useful, it could serve to distinguish Araloselachus from Carcharias and Menneroto$d u s$, but the utility is diminished because relatively few specimens possess the feature and it occurs in several species. It is interesting to note that both Mennerotodus glueckmani boktensis from Kazakhstan and Mennerotodus sp. from France exhibit serrated or pectinate cusplets (Zhelezko and Kozlov, 1999; Dutheil et al., 2006), bringing to light the possibility that these teeth actually represent Araloselachus. None of the teeth of $M$. mackayi sp. nov. exhibit serrated or pectinate cusplets, nor do any of the illustrated M. glueckmani glueckmani or M. g. usunbassi teeth. A single large M. parmleyi sp. nov. upper right lateral tooth (Fig. 8d-f) exhibits cusplets that could be described as pectinate, but they differ from the relatively low, evenly "serrated" cusplets of Araloselachus.

Several species originally placed within Mennerotodus (Zhelezko, 1994) were later moved to Borealotodus (Zhelezko and Kozlov, 1999), and the morphological differences between these two genera would seem to be slight. Additionally, the ranges of these genera overlap. No consideration seems to have been given to the possibility that tooth variation could reflect heterodonty rather than actual taxonomic variation. As described in detail above, we noted that tooth robustness in both $M$. mackayi sp. nov. and M. parm- leyi sp. nov. increases with tooth size (ontogeny or age), and there are variations in tooth morphology within the same file. Clearly the morphological criteria used to identify these genera and species need further study. However, our morphological criteria should prove useful for identifying isolated Mennerotodus teeth. If it is later determined that Mennerotodus and Borealotodus are indeed conspecific, Mennerotodus has naming priority.

Maisch et al. (2019) identified two morphologies from the Clayton Formation of Arkansas that bear similarities to Mennerotodus mackayi sp. nov. One of these was identified as Carcharias cf. whitei and the other as Carcharias sp. Although we did not directly examine their specimens, the material they show in fig. 7a-f suggests to us that their $C$. cf. whitei is consistent with what we identified as Striatolamia cf. S. cederstroemi from the Clayton Formation of Alabama. Additionally, their Carcharias sp. in fig. $7 \mathrm{~g}-\mathrm{i}$ are comparable to Mennerotodus mackayi sp. nov. (the denticles would be difficult to see without magnification). In fact, these interpretations are supported by our examination of a sample of teeth from the same locality and stratum as discussed by Maisch et al. (2019), which contains both Striatolamia cf. S. cederstroemi and Mennerotodus mackayi sp. nov. but no Carcharias teeth.

\subsection{Interpretation of the Mennerotodus dentition}

The morphologies of the various Mennerotodus teeth described herein compare closely to those of extant Carcharias taurus, and the dentitions of both of the new fossil species are based on this extant taxon. As is the case with $C$. taurus (Fig. 7a, b), the artificial dentitions we reconstructed for Mennerotodus mackayi sp. nov. and M. parmleyi sp. nov. exhibit disjunct monognathic and dignathic heterodonty. With respect to monognathic heterodonty, the upper dentition of both new species was differentiated into anterior (three files), intermediate (at least one file), and lateral and posterior files (Fig. 7c, e). The lower dentition includes anterior (four files), lateral, and posterior files (Fig. 7d, f). No intermediate teeth were identified in our M. mackayi sp. nov. sample, and posterior teeth were uncommon for both new species. We believe that this paucity is related to a collecting bias, as the morphologies would be difficult to see in the field without the aid of magnification. The number of intermediate tooth files occurring in Carcharias taurus varies from zero to four (Sadowsky, 1970), and we assume that this was true for $M$. parmleyi sp. nov. (and presumably $M$. mackayi sp. nov., for which no intermediate teeth are currently known).

For both new species of Mennerotodus, anterior teeth differ slightly from each other in overall size, and the crown of the third upper anterior tooth is often mesially curved (i.e., Fig. 7c, e). Anterior tooth root lobes become more widely separated within each file, moving distally from the symphysis, with the mesial lobe also being narrower and more elongated, and within lateral positions, crowns become shorter 

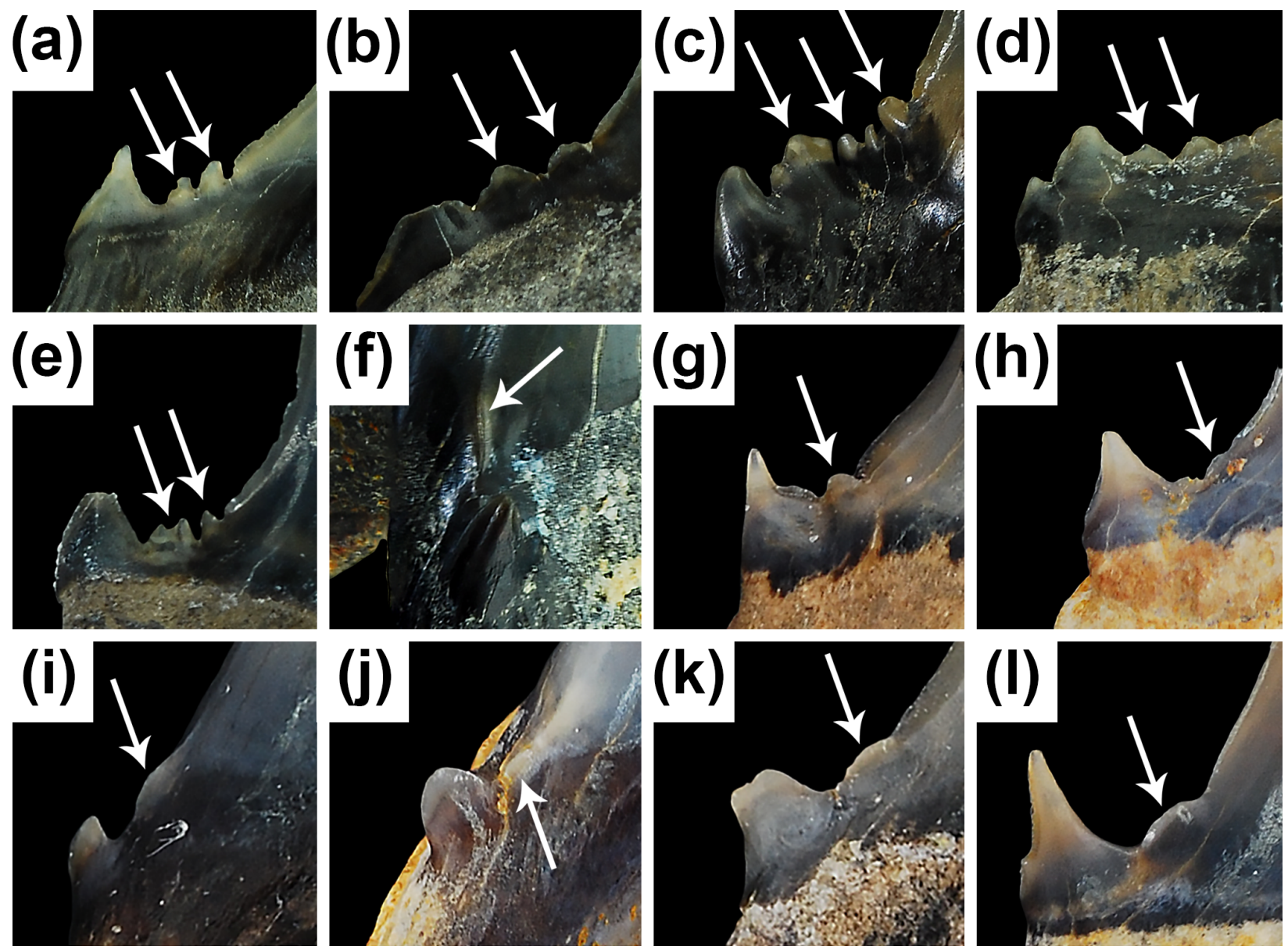

Figure 9. Variation in denticle and cusplet morphology on Mennerotodus teeth. (a-f) Mennerotodus parmleyi sp. nov. (a) SC 2013.44.125, upper right lateral tooth in labial view. (b) SC 2004.34.19, upper left lateral tooth in labial view (reversed). (c) SC 2013.44.78, fourth lower left anterior tooth in labial view. (d) SC 2004.34.185, upper right lateral tooth in labial view. (e) SC 2013.44.158, upper left lateral tooth in labial view. (f) SC2013.44.151, second lower right anterior tooth in mesial view. (g-l) Mennerotodus mackayi sp. nov., teeth in labial view. (g) MSC 42408, second upper right anterior tooth (paratype; reversed). (h) MSC 42412, upper left lateral tooth (holotype; reversed). (i) MSC 42410, third lower right anterior tooth (paratype; reversed). (j) MSC 42405, second lower right anterior tooth (paratype; reversed). (k) MSC 42406, fourth lower left anterior tooth (paratype). (l) MSC 42409, lower right lateral tooth (paratype; reversed).

and more distally inclined towards the jaw hinge, particularly in the upper jaw (compare Fig. 7a, c, e). Root lobes are shorter but wider than observed on anterior teeth and more widely separated. We could not confidently assign lateral teeth to a specific file beyond the first lateral file because crown size reduction and inclination towards the commissure appear to have been gradual. The number of lateral tooth files varies in extant $C$. taurus (Applegate, 1965; Lucifora et al., 2003), and we presume that a similar number of files (from five to seven, excluding posterior files) was present in Mennerotodus dentitions. On SC86.62.2 and SC2000.20.6, overall tooth size is sharply reduced, and crowns are very sharply distally inclined after the seventh upper lateral file, and a similar tooth size reduction was observed after the fifth or sixth lower lateral file (Fig. 7a, b). We consider these smaller teeth as being part of posterior files. The diminutive posterior teeth in our samples for each of the new species are attributed to the lower jaw (Fig. 7c-f) because they have vertical or only slightly distally inclined crowns (see below).

Dignathic heterodonty is evident in the anterior files of both new species, as the upper teeth are more sigmoidal (there is a stronger S-shaped curvature) than on lower teeth. The root lobes of upper anterior teeth are slightly wider and shorter than those of the lower jaw, and the interlobe area of upper anterior teeth is more rounded than seen on lower anterior files (compare Figs. 3 and 4, 5 and 6). In the lateral files, the main cusp of upper teeth is broader and distally inclined, whereas those of lower laterals are comparatively narrower and more erect. The root lobes of upper lateral teeth have a more rectangular appearance and are more pointed than those of lower teeth. In general, the root lobes of lower teeth are more elongated than on teeth of the upper jaw. Very few lat- 
eral teeth of either new species exhibit two pairs of lateral cusplets, but within $M$. parmleyi sp. nov. we observed that most of those with two pairs are from the lower dentition. We presume that upper posterior teeth were conspicuously distally inclined, based on our observations of extant Carcharias taurus dentitions (SC86.62.2 and SC2000.20.6), as opposed to rather erect as seen on SC2004.34.181 (Fig. 6ab, ac).

Both new Mennerotodus species exhibit ontogenetic heterodonty, which is expressed as an increase in overall tooth size and robustness within each file. When compared to each other, the average-sized $M$. parmleyi sp. nov. upper right lateral tooth shown in Fig. 7b has a more gracile crown and root compared to the much larger specimen shown in Fig. 7e. Additionally, the large third upper left anterior tooth shown in Fig. $7 \mathrm{~h}$ is more robust than the smaller specimens shown in Fig. $7 \mathrm{j}$ and 1 . Similar variations were observed in $M$. mackayi sp. nov., as for example illustrated in Fig. $7 \mathrm{~m}$ and o, where the smaller second lower right anterior tooth (Fig. $7 \mathrm{~m}$ ) is more gracile and has subparallel cutting edges, whereas the larger one (Fig. 7o) has a broader crown and biconvex cutting edges. The same holds true for the third upper anterior position, as Fig. $7 \mathrm{q}$ shows a rather gracile specimen compared to the larger one in Fig. 7s.

Interestingly, we found that the presence of lingual ornamentation and/or denticulation on the teeth of Mennerotodus mackayi sp. nov. and M. parmleyi sp. nov. is not dependent on tooth size or jaw position, as these features can occur on anterior and lateral teeth of all sizes. The denticulation we observed is variable and best developed on lateral teeth. On both upper and lower lateral teeth of M. parmleyi sp. nov., the denticulation can be expressed as one or more tiny roundedto-pointed projections located at the very base of the cutting edge (Fig. 9a-e) of the main cusp and sometimes on the medial side of the lateral cusplet (Fig. 9d, f). The denticulation on $M$. mackayi sp. nov. is much more subtle and generally expressed as a single sharp denticle (Fig. 9g, h) or an elongated convex cutting edge (Fig. 9k, l). At the base of the main cusp of anterior teeth of both new species, a small tubercle may be seen (Fig. 9i, j) or, more commonly, a short and sharp edge that is clearly separated from the main cutting edge may occur (Fig. 9f). We consider these structures as analogous to the denticles occurring on lateral teeth, and we included anterior teeth with tubercles and/or short ridges in our count of teeth possessing denticles. In all tooth positions, the feature is usually more prominent on the mesial side of the crown.

Only $30 \%$ of the teeth in both the M. mackayi sp. nov. and $M$. parmleyi sp. nov. samples exhibit denticulation, and when present these features are usually difficult to see without the aid of magnification. The presence of lingual ornamentation is also a challenge to discern with the naked eye, and if present, it ranges from barely perceptible to moderately well developed. Those specimens in our samples that lack denticles were identified as Mennerotodus because they are otherwise morphologically identical to teeth possessing denticles. Similarly, teeth bearing denticles may be smooth or bear lingual crown ornamentation. Within both species, the development of denticles does not appear to be related to ontogeny, as this feature may be present or absent on small and large teeth from the same tooth file (Fig. $8 \mathrm{~g}$ and k, $\mathrm{n}$ and $\mathrm{p}, \mathrm{r}$ and $\mathrm{t}$ ).

\subsection{Additional North American occurrences of Mennerotodus}

We found that Mennerotodus mackayi sp. nov. and M. parmleyi sp. nov. are not restricted to their respective type localities or type strata. A small sample of teeth made available to us by MMNS shows that $M$. mackayi sp. nov. occurs in the Clayton Formation of Hot Spring County, Arkansas, USA, and we believe that the teeth previously identified as Carcharias cf. whitei (Becker et al., 2011) and Carcharias sp. (Maisch et al., 2019) are actually M. mackayi sp. nov. This new species was also found stratigraphically higher within the Clayton Formation and in slightly younger deposits of the Porters Creek Formation in Alabama (JAE, personal observation). These occurrences demonstrate that $M$. mackayi sp. nov. is present within multiple Danian units in Alabama (zones NP1 to NP4) and in the Clayton Formation of Arkansas.

Ebersole et al. (2019) were the first to recognize Mennerotodus within an elasmobranch paleofauna of the USA. Their material was derived from the middle Eocene (Bartonian, lower part of Zone NP17) Gosport Sand, which appears to be time equivalent to the Clinchfield Formation of Georgia. Comparison of the Alabama specimens to teeth of $M$. parmleyi sp. nov. from Georgia revealed that the material is conspecific.

As part of our study we directly examined the sample of odontaspidid teeth $(n=34)$ that Westgate (1984) reported and originally identified as Odontaspis hopei (Agassiz, 1843). These specimens were collected from strata exposed along Crow Creek in St Francis County, Arkansas, but the fossiliferous unit has not been specifically identified (Westgate, 1984, 2012; Westgate and Emry, 1985). However, the Crow Creek beds have been correlated to the Jacksonian (late Eocene) Moodys Branch Formation (upper part of NP17) and the Yazoo Clay (Priabonian; Westgate, 2012). Based on our inspection of Westgate's (Westgate, 1984) Odontaspis hopei specimens, we conclude that they are also conspecific with Mennerotodus parmleyi sp. nov. This occurrence is therefore the youngest temporal record of M. parmleyi sp. nov., but a more precise age remains to be determined. A detailed analysis of known Moodys Branch Formation elasmobranch faunas from the Gulf Coastal Plain has yet to be undertaken.

Mennerotodus is not yet known to occur in the elasmobranch paleofaunas from the Yazoo Clay (NP18-NP21) of Alabama (JAE, personal observation) or the Parkers Ferry (NP19-NP20) and Harleyville (NP21) formations of South 
Carolina (DJC, personal observation). It is possible that odontaspidid teeth from the Priabonian Dry Branch Formation (NP19-NP20) of South Carolina represent Mennerotodus parmleyi sp. nov., but the material is imperfectly preserved (Cicimurri and Knight, 2019). We did not directly examine the specimens, and no description or illustration makes the presence of denticulation clear, but teeth illustrated by Case (1981) that were identified as Odontaspis acutissima are quite similar to M. parmleyi sp. nov. as shown in our reconstructed dentition (Fig. 7e, f). In our opinion, the teeth shown by Case (1981) include a second upper right anterior tooth (in fig. 2.6), an upper right lateral tooth (in figs. 2.7 and 3.1), a third lower left anterior tooth (in fig. 2.8), and a first lower left anterior tooth (in fig. 3.2). Similarly, specimens identified as Odontaspis cuspidata by Case and Borodin (2000, p. 8 and pl. 1.3-1.7) from Twiggs Clay facies of the Dry Branch Formation of Georgia appear to represent various upper and lower anterior teeth of Mennerotodus parmleyi sp. nov.

\section{Conclusions}

Two new species of Mennerotodus are described from Paleogene deposits of the Atlantic and Gulf coastal plains. One species, $M$. mackayi sp. nov., occurs in the lower Paleocene (Danian) Clayton and Porters Creek formations of Alabama and Arkansas. The type material for the second species, $M$. parmleyi sp. nov., is from the late middle Eocene (Bartonian) Riggins Mill Member of the Clinchfield Formation of central Georgia. This taxon also occurs in the roughly contemporaneous Gosport Sand of Alabama and potentially in the slightly younger Moodys Branch Formation in St Francis County, Arkansas. The available data indicate that Mennerotodus parmleyi sp. nov. is restricted to the southeastern US Atlantic and Gulf coastal provinces, during the time represented by Zone NP17. It is interesting to note that $M$. parmleyi sp. nov. appears to be absent from the approximately time-equivalent Tupelo Bay Formation of South Carolina (DJC, personal observation). Mennerotodus mackayi sp. nov. is thus far only known from Alabama and Arkansas, but it may also occur at other sites within the Mississippi Embayment where the Clayton Formation is exposed (i.e., Mississippi, southern Illinois). Temporally equivalent paleofaunas in the Atlantic Coastal Plain, like those reported from the Hornerstown Formation of New Jersey (Case, 1996) or Brightseat Formation of Maryland (Kent, 1994), need to be re-evaluated for the presence of Mennerotodus. The Danian occurrence of M. mackayi sp. nov., within $10 \mathrm{~m}$ of the K-Pg boundary, represents the oldest record of Mennerotodus and could indicate a North American origin for the genus.

Mennerotodus dentitions appear to have been very similar to that of extant Carcharias taurus, but subtle morphological differences can be used to differentiate isolated teeth of the two genera. Based on our analysis of the two new Mennero- todus species, the presence of denticulation at the base of the main cusp, a feature previously considered as a characteristic of the genus, was documented on only $30 \%$ of the samples. Denticles on M. mackayi sp. nov. are particularly difficult to see without the aid of magnification. These facts, combined with the overall close similarity to teeth of other genera, has contributed to the lack of recognition of Mennerotodus in elasmobranch paleofaunas. We believe that Mennerotodus is more widespread, both temporally and geographically, than is currently known, and future records are likely to be documented.

Data availability. The type and referred material for M. mackayi sp. nov is housed in the scientific collections at McWane Science Center, Birmingham, Alabama, USA. The type and referred material for M. parmleyi sp. nov is housed in the scientific collections at the South Carolina State Museum, Columbia, USA.

Author contributions. DJC collected the M. parmleyi sp. nov specimens, conducted the analysis, and wrote the paper. JAE conducted the analysis, wrote the paper, and prepared the figures. GM conducted the analysis and collected the M. mackayi sp. nov specimens.

Competing interests. The authors declare that they have no conflict of interest.

Acknowledgements. The authors thank Sandy M. Ebersole of the Geological Survey of Alabama, Tuscaloosa, USA, for access to GIS shapefiles used in the production of Figs. 1-2. Amanda Millhouse of the United States National Museum of Natural History, Washington, DC, USA, is thanked for loaning us material from the Crow Creek locality in Arkansas. George Phillips of the Mississippi Museum of Natural Science (MMNS), Jackson, USA, is thanked for loaning us specimens from site ALn-13 and from Danian localities in Arkansas. Carson Sloan of the Arkansas Department of Transportation is thanked for collecting and donating specimens to the MMNS for us to examine. Finally, we thank Pieter J. De Schutter and Sebastian Stumpf for their critical review of an earlier version of this work and Florian Witzmann and Natascha Töpfer for their efforts during the review and publication process.

Review statement. This paper was edited by Florian Witzmann and reviewed by Pieter J. De Schutter and Sebastian Stumpf.

\section{References}

Agassiz, L.: Recherches sur les poissons fossils, Neuchâtel, Switzerland, https://doi.org/10.5962/bhl.title.4275, 1843.

Albright, L. B., III, Sanders, A. E., Weems, R. E., Cicimurri, D. J., and Knight, J. L.: Cenozoic vertebrate biostratigraphy of South 
Carolina, USA, and additions to the fauna, Bulletin of the Florida Museum of Natural History, 57, 77-236, 2019.

Applegate, S. P.: Tooth terminology and variation in sharks with special reference to the sand shark Carcharias taurus Rafinesque, Contributions to Science, Los Angeles County Museum, 86, 1-18, 1965.

Becker, M. A., Smith, L. C., and Chamberlain Jr., J. A.: Chondrichthyans from the Clayton Limestone unit of the Midway Group (Paleogene: Paleocene) of Hot Spring County, Arkansas, USA, Cainozoic Research, 8, 13-28, 2011.

Berg, L.: System der rezenten und fossilen Fischartigen und Fische, VEB Verlag der Wissenschaften, Berlin, Germany, 1958.

Bigelow, H. B. and Schroeder, W. C.: Fishes of the western North Atlantic, part 1: Lancelets, Cyclostomes, Sharks, Memoirs of the Sears Foundation for Marine Research, 1, 59-576, 1948.

Bonaparte, C. L.: Selachorum tabula analytica, Nuovi Annali della Scienze Naturali, Bologna, 1, 195-214, 1838.

Cappetta, H.: Handbook of Paleoichthyology, Vol. 3B, Chondrichthyes II, Gustav Fischer Verlag, Stuttgart, Germany, 1987.

Cappetta, H.: Chondrichthyes, Mesozoic and Cenozoic Elasmobranchii: Teeth, in: Handbook of Paleoichthyology, 3E, edited by: Schultze, H.-P. and Kuhn, O., Friedrich Pfeil, Munich, Germany, 2012.

Cappetta, H. and Nolf, D.: Révision de quelques Odontaspididae (Neoselachii: Lamniformes) du Paléocène et de l'Eocène du Bassin de la Mer du Nord, Bulletin de l'Institut Royal des Sciences Naturelles de Belgique, Science de la Terre, 75, 237-266, 2005.

Case, G. R.: Late Eocene selachians from South-central Georgia, Palaeontogr. Abt. A, 176, 52-79, 1981.

Case, G. R.: A new selachian fauna from the Lower Hornerstown Formation (Early Paleocene/Montian) of Monmouth County, New Jersey, Palaeontogr. Abt. A, 242, 99-126, 1996.

Case, G. R. and Borodin, P. D.: Late Eocene selachians from the Irwinton Sand Member of the Barnwell Formation (Jacksonian), WKA mines, Gordon, Wilkinson County, Georgia, Münchner Geowissenschaftliche Abhandlungen, 39, 5-16, 2000.

Cicimurri, D. J. and Knight, J. L.: Late Eocene sharks and rays from the Dry Branch Formation (Priabonian) of Aiken County, South Carolina, PaleoBios, 36, 1-31, 2019.

Compagno, L. J. V.: Interrelationships of living elasmobranchs, Zool. J. Linn. Soc.-Lond., 53, 15-61, 1973.

Cope, E. D.: Contribution to the ichthyology of the Lesser Antilles, T. Am. Philos. Soc., 14, 445-483, 1871.

Cunningham, S.: A comparison of isolated teeth of early Eocene Striatolamia macrota (Chondrichthyes, Lamniformes), with those of a Recent sand shark, Carcharias taurus, Tertiary Research, 20, 17-31, 2000 .

De Schutter, P. J.: Carcharias vorax (Le Hon, 1871) (Chondrichthyes, Lamniformes), from the Miocene of Belgium: redescription and designation of a neotype and paraneotype, Geol. Belg., 14, 175-192, 2011.

Dutheil, D. B., Moreau, F., and De Plöeg, G.: Les ichthyofaunes du gisement à ambre de Le Quesnoy (Paléocène et Éocène du bassin de Paris, France), Cossmanniana, 11, 1-13, 2006.

Ebersole, J. A., Cicimurri, D. J., and Stringer, G. L.: Taxonomy and biostratigraphy of the elasmobranchs and bony fishes (Chondrichthyes and Osteichthyes) of the lower-to-middle Eocene (Ypresian to Bartonian) Claiborne Group in Alabama, USA, including an analysis of otoliths, Eur. J. Taxon., 585, 1-274, https://doi.org/10.5852/ejt.2019.585, 2019.

Glickman, L. S.: Sharks of Paleogene and their stratigraphic significance, Nauka Press, Moscow, 1964 (in Russian).

Guitart-Manday, D. J.: Nuevo nombre para una especie de Tiburón del género Isurus (Elasmobranchii: Isuridae) de Aguas Cubanas, Poeyana, series A, 15, 1-9, 1966.

Hay, O. P.: Bibliography and catalogue of the fossil Vertebrata of North America, Bulletin of the United States Geological and Geographical Survey of the Territories, 179, 1-868, https://doi.org/10.5962/bhl.title.20094, 1902.

Huddleston, P. F. and Hetrick, J. H.: Upper Eocene stratigraphy of central and eastern Georgia, Georg. Geol. Surv. Bull., 95, 1-78, 1986.

Huxley, T. H.: On the application of the laws of evolution to the arrangement of the vertebrata and more particularly of the mammalia, P. Zool. Soc. Lond., 1880, 649-662, 1880.

Kent, B. W.: Fossil Sharks of the Chesapeake Bay Region. Egan Rees and Boyer, Incorporated, Columbia, Maryland, USA, 1994.

Kent, B. W.: The cartilaginous fishes (chimaeras, sharks, and rays) of Calvert Cliffs, Maryland, USA, in: The geology and vertebrate paleontology of Calvert Cliffs, Maryland, edited by: Godfrey, S. J., Smithsonian Contributions to Paleobiology, 100, 45-157, 2018.

Le Hon, H.: Préliminaires d'un mémoire sur les poissons tertiaires de Belgique, minaire d'un mémoire sur les poissons fossiles tertiaires de Belgique, 1-15, 1871.

Leriche, M.: Les poisons éocènes de la Belgique, Mémoires du Musée Royal d'Histoire Naturelle de Belgique, 3, 49-228, 1905.

Lesueur, C. A.: Description of a Squalus, of a very large size, which was taken on the coast of New Jersey, J. Acad. Nat. Sci. Philos., 2, 343-352, 1822.

Linnaeus, C.: Systema Naturae per regna tria naturae, regnum animale, secundum classes, ordines, genera, species, cum characteribus differentiis synonymis, locis, L. Salvius, Stockholm, Sweden, 1758.

Lucifora, L. O., Cione, A. L., Menni, R. C., and Escalante, A. H.: Tooth row counts, vicariance, and the distribution of the sand tiger shark Carcharias taurus, Ecography, 26, 567-572, https://doi.org/10.1034/j.1600-0587.2003.03532.x, 2003.

Maisch, H. M., IV, Becker, M. A., and Griffiths, M. L.: Chondrichthyans from the Lower Clayton Limestone Unit of the Midway Group (Paleocene) near Malvern, Arkansas, USA, with comments on the $\mathrm{K} / \mathrm{Pg}$ boundary, Paläontol. Z., https://doi.org/10.1007/s12542-019-00494-7, 2019.

Malyshkina, T.: Late Eocene scyliorhinid sharks from the TransUrals, Russia, Acta Palaeontol. Pol., 51, 465-475, 2006a.

Malyshkina, T. P.: Elasmobranchs of the western margin of the West Siberian Paleogene basin, Ekaterinburg, Russia, 2006b (in Russian).

Mancini, E. A.: Lithostratigraphy and biostratigraphy of Paleocene subsurface strata in southwest Alabama, Gulf Coast Assoc. Geol. Soc. Trans., 31, 359-367, 1981.

Mancini, E. A. and Tew, B. H.: Tertiary sequence stratigraphy and biostratigraphy of southwestern Alabama, in: Guidebook for Field Trip 1, 39th Annual Meeting, Southeastern Section, Geol. Soc. Am., Tuscaloosa, 1990. 
Mancini, E. A., Tew, B. H., and Smith, C. C.: Cretaceous-Tertiary contact, Mississippi and Alabama, J. Foramin. Res., 19, 93-104, 1989.

Menner, V. V.: Les sélaciens du Paléogène de Manghyschlack, d'Emba et du versant oriental d'Oural, Bulletin de la Société Impériale des Naturalistes de Moscou, Section Géologique, 6, 292-338, 1928.

Müller, J. and Henle, F. G. J.: Systematische Beschreibung der Plagiostomen, Veit and Company, Berlin, Germany, https://doi.org/10.5962/bhl.title.6906, 1841.

Nelson, J. S., Grande, T. C., and Wilson, M. V. H.: Fishes of the World, 5th edition, John Wiley and Sons, Incorporated, Hoboken, New Jersey, 2016.

Parmley, D. and Cicimurri, D. J.: Late Eocene sharks of the Hardie Mine local fauna of Wilkinson County, Georgia, Georgia J. Sci., 61, 153-179, 2003.

Pollerspöck, J. and Gille, D.: Erster Fossilnachweis eines MeersauHais aus Deutschland, Fossilien, 35, 16-21, 2018.

Purdy, R. W., Schneider, V. P., Applegate, S. P., McLellan, J. H., Meyer, R. I., and Slaughter, B. H.: Neogene sharks, rays, and bony fishes from Lee Creek Mine, Aurora, North Carolina, in: Geology and Palaeontology of the Lee Creek Mine, North Carolina, III, edited by: Ray, C. E. and Bohaska, D., Sm. C. Geol., 90, 71-202, https://doi.org/10.5479/si.00810266.90, 2001.

Rafinesque, C. S.: Caratteri di alcuni nuovi generi e nuove specie di animali e pinate della Sicilia, con varie osservazioni sopra i medisimi, lère partie, Per le stampe de Sanfilippo, Palermo, Italy, https://doi.org/10.5962/bhl.title.104418, 1810.

Raymond, D. E., Osborne, W. E., Copeland, C. W., and Neathery, T. L.: Alabama stratigraphy, Geological Survey of Alabama, Circular, 140, 1-97, 1988.

Reinecke, T. and Radwański, A.: Fossil sharks and batoids from the Korytnica-clays, early Badenian (Langhian, Middle Miocene), Fore-Carpathian basin, central Poland - a revision and updated record, Palaeontos, 28, 1-32, 2015.

Reinecke, T., Stapf, H., and Raisch, M.: Die Selachier und Chimären des Unteren Meesressandes und Schleichsandes im Mainzer Becken (Alzey-und Stadecken Formation, Rupelium, Unteres Oligozän), Palaeontos, 1, 1-73, 2001.

Sadowsky, V.: On the dentition of the sand shark, Odontaspis taurus, from the vicinity of Cananeia, Brazil, Boletim do Instituto Oceanográfico, 18, 37-44, 1970.

Savrda, C. E.: Ichnosedimentologic evidence for a noncatastrophic origin of Cretaceous-Tertiary boundary sands in Alabama, Geology, 21, 1075-1078, https://doi.org/10.1130/00917613(1993)021<1075:IEFANO>2.3.CO;2, 1993.

Shimada, K.: Notes on the dentition of the bigeye sandtiger shark, Odontaspis noronhai (Lamniformes: Odontaspididae), J. Fossil Res., 34, 15-17, 2001.

Shimada, K.: Dental homologies in lamniform sharks (Chondrichthyes: Elasmobranchii), J. Morphol., 251, 38-72, https://doi.org/10.1002/jmor.1073, 2002a.

Shimada, K.: The relationship between the tooth size and total body length in the shortfin mako, Isurus oxyrinchus (Lamniformes: Lamnidae), J. Fossil Res., 35, 6-9, 2002 b.

Shimada, K.: The relationship between the tooth size and total body length in the white shark, Carcharodon carcharias (Lamniformes: Lamnidae), J. Fossil Res., 35, 28-33, 2002c.
Shimada, K.: The relationship between the tooth size and total body length in the sandtiger shark, Carcharias taurus (Lamniformes: Odontaspididae), J. Fossil Res., 37, 76-81, 2004.

Siverson, M.: Revision of the Danian cow sharks, sand tiger sharks, and goblin sharks (Hexanchidae, Odontaspididae, and Mitsukurinidae) from Southern Sweden, J. Vertebr. Paleontol., 15, 1-12, https://doi.org/10.1080/02724634.1995.10011203, 1995.

Siverson, M.: A new large lamniform from the uppermost Gearle Siltstone (Cenomanian, Late Cretaceous) of Western Australia, T. R. S. E. Earth., 90, 49-66, https://doi.org/10.1017/S0263593300002509, 1999.

Stromer, E.: Reptilien und Fischreste aus dem marinen Alttertiär von Südtogo (West Africa), Monatsbericht der deutschen geologischen Gesellschaft, 62, 478-505, 1910.

Szabó, M. and Kocsis, L.: A new middle Miocene selachian assemblage (Chondrichthyes, Elasmobranchii) from the central Paratethys (Nyirád, Hungary): implications for temporal turnover and biogeography, Geol. Carpath., 67, 573-594, https://doi.org/10.1515/geoca-2016-0036, 2016.

Udgata, D. B. P.: Glauconite as an indicator of sequence stratigraphic packages in a lower Paleocene passive-margin shelf succession, central Alabama, Unpublished M.S. thesis, Auburn University, Auburn, 2007.

Van den Eeckhaut, G. and De Schutter, P.: The elasmobranch fauna of the Lede Sand Formation at Oosterzele (Lutetian, Middle Eocene of Belgium), Palaeofocus, 1, 1-57, 2009.

Ward, D. J.: Hypotodus verticalis (Agassiz 1843), Hypotodus robustus (Leriche 1921) and Hypotodus heinzelini (Casier 1967), Chondrichthyes, Lamniformes, junior synonyms of Carcharias hopei (Agassiz 1843), Tertiary Research, 10, 1-12, 1988.

Westgate, J. W.: Lower vertebrates from the Late Eocene Crow Creek Local Fauna, St. Francis County, Arkansas, J. Vertebr. Paleontol., 4, 536-546, https://doi.org/10.1080/02724634.1984.10012029, 1984.

Westgate, J. W.: Palaeoecology of a primate-friendly, middle Eocene community from Laredo, Texas and a review of stratigraphic occurrences of Paleogene land mammals across the Gulf Coastal Plain, USA, Palaeobio. Palaeoenv., 92, 497-505, https://doi.org/10.1007/s12549-012-0084-6, 2012.

Westgate, J. W. and Emry, R. J.: Land mammals of the Crow Creek Local Fauna, Late Eocene, Jackson Group, St. Francis County, Arkansas, J. Paleontol., 59, 242-248, 1985.

Winkler, T. C.: Mémoire sur quelques restes de poissons du système heersien, Archives du Musée Teyler, 4, 1-15, 1874.

Zhelezko, V. I.: Phylogenesis of Lamnoid sharks of the Palaeogene and their significance for zonal stratigraphy in phylogenetic aspects of palaeontology, Academy of Science USSR, All-Union Palaeontological Society, Leningrad, 16-17, 1989 (in Russian).

Zhelezko, V. I.: Sharks of family Jaekelotodontidae of European and middle Asian paleobiogeographic provinces, Bulletin of the Moscow Society of Naturalists, 69, 47-62, 1994.

Zhelezko, V. I. and Kozlov, V. A.: New Information about the geology of the Urals, western Siberia and Kazakhstan, Dokl. Akad. Nauk SSSR, 174-181, 1990.

Zhelezko, V. I. and Kozlov, V. A.: Elasmobranchii and Palaeogene biostratigraphy of Trans Urals and central Asia, Russian Academy of Science, Urals Branch, 3, 1-323, 1999 (in Russian). 